Florida International University FIU Digital Commons

$3-22-2010$

\title{
The Perceptions, Attitudes and Practices of Registered Dietitians Regarding Functional Foods
}

Amanda Berhaupt

Florida International University, amanda.berhaupt@gmail.com

DOI: $10.25148 /$ etd.FI10041629

Follow this and additional works at: https://digitalcommons.fiu.edu/etd

Part of the Nutrition Commons

\section{Recommended Citation}

Berhaupt, Amanda, "The Perceptions, Attitudes and Practices of Registered Dietitians Regarding Functional Foods" (2010). FIU Electronic Theses and Dissertations. 156.

https://digitalcommons.fiu.edu/etd/156 


\title{
FLORIDA INTERNATIONAL UNIVERSITY
}

Miami, Florida

\section{THE PERCEPTIONS, ATTITUDES AND PRACTICES OF REGISTERED DIETITIANS REGARDING FUNCTIONAL FOODS}

\author{
A thesis submitted in partial fulfillment of the \\ requirements for the degree of \\ MASTER OF SCIENCE \\ in \\ DIETETICS AND NUTRITION \\ by
}

Amanda Berhaupt

2010 
To: Dean Fernando M. Treviño

R.Stempel College of Public Health and Social Work

This thesis, written by Amanda Berhaupt, and entitled The Perceptions, Attitudes and Practices of Registered Dietitians Regarding Functional Foods, having been approved in respect to style and intellectual content, is referred to you for judgment.

We have read this thesis and recommend that it be approved.

Zisca Dixon

Barbara Thomlison

Evelyn B. Enrione, Major Professor

Date of Defense: March 22, 2010

The thesis of Amanda Berhaupt is approved.

Dean Fernando M. Treviño R.Stempel College of Public Health and Social Work

Interim Dean Kevin O'Shea University Graduate School

Florida International University, 2010 
(C) Copyright 2010 by Amanda Berhaupt

All rights reserved. 


\section{DEDICATION}

I dedicate this thesis to my husband, Jesse Glickstein, my parents Suzanne Gold and John Berhaupt, and Joanie and Gary Glickstein. Their love and unwavering support, gave me the strength to complete this thesis. 


\section{ACKNOWLEDGMENTS}

I wish to thank the Registered Dietitians who participated in my survey, without your participation, this thesis would not have been possible. I would also like to thank the members of my committee, Dr. Zisca Dixon and Dr. Barbara Thomlison for their confidence in and dedication to the completion of my thesis. Many thanks to Dr. Fatma Huffman and the Department of Dietetics and Nutrition at Florida International University for believing in this project and supporting my endeavors. Thank you to the Miami Dietetic Association for their support. I would also like to thank Dr. Johnson for her patience, assistance and good nature throughout this process.

I am grateful for my family, Jesse Glickstein who helped in every step of this process and took ownership in my success, Suzanne Gold who has always been my biggest cheerleader, and Joan Glickstein who greatly helped with editing.

Special thanks to Dr. Evelyn Enrione, my major professor, who was willing to teach and guide me throughout this process. 
ABSTRACT OF THE THESIS

THE PERCEPTIONS, ATTITUDES AND PRACTICES OF REGISTERED

DIETITIANS REGARDING FUNCTIONAL FOODS

\author{
by
}

Amanda Berhaupt

Florida International University, 2010

Miami, Florida

Professor Evelyn B. Enrione, Major Professor

The term "functional food" (FF) has a variety of definitions resulting in term ambiguity. It is unclear Registered Dietitians' (RDs) understanding and practices about FF. A descriptive, cross-sectional study investigated RDs' perceptions, attitudes and practices regarding FF. A national random sample $(n=1800)$ of $R D s$ was mailed a FF questionnaire, 385 (22\%) responded. Given five definitions from food-nutrition authorities, the majority of RDs did not agree on a definition, although three-fourths $(\mathrm{n}=292,75.8 \%)$ perceived fortified foods as FF. Registered Dietitians agreed FF could improve health $(\mathrm{n}=266,69.1 \%)$, prevent disease $(\mathrm{n}=282,73.2 \%)$ and treat clientele $(\mathrm{n}=246,63.9 \%)$, however were neutral $(41.6 \%)$ or disagreed $(37.7 \%) \mathrm{FF}$ were herbs, or equivalent to medicine $(32.7 \%, 49.2 \%$ respectively). Most RDs ( $\mathrm{n}=290,75.9 \%)$ ate FF; fewer $(\mathrm{n}=231,61.4 \%)$ professionally recommended them. Nearly all $(\mathrm{n}=353)$ indicated interest in learning about FF. Registered Dietitians revealed inconsistencies between their perceptions, attitudes and practices regarding FF. Professional education is needed to resolve discrepancies regarding FF. 


\section{TABLE OF CONTENTS}

CHAPTER

I. INTRODUCTION

II. LITERATURE REVIEW

4

Oregon Study

Pennsylvania Study

Canada Study

Holland Study

Summary of Literature

Conclusion

III. METHODOLOGY

Sample

Instrument

Perceptions Section

Attitudes Section

Practices Section

Nutrition Information Source Section

Demographics Section

Pilot Study

Expert Panel

Data Collection

Statistical Analyses

IV. RESULTS

Demographics

Perceptions

Attitudes

Practices

Nutrition Information Source

V. DISCUSSION

Demographics

Perceptions

Attitudes

Practices

Nutrition Information Source

Research Questions

Limitations

Recommendations

42

Future Research

42

Conclusion 
LIST OF REFERENCES

APPENDICES 


\section{LIST OF TABLES}

TABLE

PAGE

Table 1. Demographic characteristics of respondents who completed a national survey: perceptions, attitudes and practices of Registered Dietitians regarding functional foods

Table 2. Registered Dietitians who either selected one of five functional food definitions or "I don't know"

Table 3. Definition choices of Registered Dietitians according to their education

Table 4. Definition choices of Registered Dietitians based on the region where they practiced

Table 5. Foods Registered Dietitians selected as functional foods MyPyramid food groups

Table 6. Vitamins, minerals and dietary supplements Registered Dietitians considered functional foods

Table 7. Agreement of Registered Dietitians with functional food statements based on their education

Table 8. Agreement of Registered Dietitians with functional food statements according to their region of practice

Table 9. Registered Dietitians' personal consumption, and professional recommendation of functional foods

Table 10. Three identified functional foods Registered Dietitians personally consumed or professionally recommended in the past year, based on written response

Table 11. Registered Dietitians' purposes for professionally recommending functional foods to patients and/or clients in the past year

Table 12. Registered Dietitians' purposes for professionally recommending functional foods to patients and/or clients in the past year, according to education 
Table 13. Registered Dietitians' purposes for professionally recommending functional foods to patients and/or clients in the past year, according to region of practice

Table 14. Source where Registered Dietitians' learned about functional foods 


\section{LIST OF FIGURES}

FIGURE

PAGE

Figure 1. Food categories Registered Dietitians considered functional foods.

Figure 2. Responses of Registered Dietitians to the statement, "Functional Foods Are Effective In Preventing Disease and Promoting Health"

Figure 3. Responses of Registered Dietitians to the statement, "All Foods are Functional"

Figure 4. Responses of Registered Dietitians to the statement, "Functional Foods Improve Health"

Figure 5. Responses of Registered Dietitians to the statement, "Functional Foods Provide Benefit Beyond Basic Nutrients"

Figure 6. Responses of Registered Dietitians to the statement, "Functional Foods Should be Included as Part of a Treatment Plan for my Clients/Patients"

Figure 7. Responses of Registered Dietitians to the statement, "Functional Foods Are Equal To Medication"

Figure 8. Responses of Registered Dietitians to the statement, "Herbs Should Be Used As Functional Foods"

Figure 9. Training and education formats chosen by Registered Dietitians to learn about functional foods, based on multiple responses 


\section{INTRODUCTION}

In the early 1990s, the Japanese government conceptualized 'foods for specified health use,' otherwise termed functional foods, to prevent disease and keep healthcare costs low $(1,2,3)$. The term "functional food" has since expanded to the United States (US) and other parts of the world. A well-documented aspect of functional foods is a lack of a cohesive definition $(4,5,6,7,8)$. Food and nutrition authorities in the US have not reached a consensus regarding definitions or types of food, resulting in an ambiguity about functional foods $(5,6,7,8,9)$. This ambiguity makes it difficult for Registered Dietitians (RDs) to acquire a comprehensive understanding of functional foods and as a result, are unable to impart correct knowledge to their clientele.

In the US, the American Dietetic Association (ADA), the International Life Sciences Institute of North America (ILSINA), and the Food and Nutrition Board (FNB) of the Institute of Medicine all have different working definitions of functional food, while the Food and Drug Administration (FDA) does not provide any definition. The ADA “...classifies all foods as functional at some physiologic level..." citing that "...whole foods, fortified foods, enriched or enhanced foods, have a potentially beneficial effect on health when consumed as part of a varied diet" $(4,5)$. The FNB describes functional foods as "... any modified food or food ingredient that may provide a health benefit beyond that of the traditional nutrients it contains" (4). The ILSINA states that functional foods are "those that by virtue of physiologically active food components provide health benefits beyond basic nutrition" (10). The FDA does not provide a definition, nor does it recognize functional foods as a regulatory category. It does maintain they are regulated under the Federal Food Drug and Cosmetic Act $(5,9,11)$. 
International authorities have different definitions as well. The European branch of the International Life Sciences Institute (ILSI) funded the European Union project, Functional Food Science in Europe (FUFOSE). The FUFOSE classifies functional foods as those that have "satisfactorily demonstrated to affect beneficially one or more target functions in the body, beyond adequate nutritional effects in a way that is relevant to either an improved state of health and well-being and/or reduction of risk of disease" (12). Japan identifies them as those foods "composed of functional ingredients that affect the structure and/or function of the body and are used to maintain or regulate specific health conditions" (13). Currently, Japan is the only government that regulates functional foods (5).

While all definitions, both nationally and internationally, exhibit similarity in providing an "advantage to consumers in some functional way," they are not synonymous $(6,14,15)$. The verbiage, intent, meaning and professional interpretation of the definitions are different as to which foods and/or food components are functional. However, all definitions stress that functional foods contain added health benefits.

Registered Dietitians, as the nutrition experts, are responsible for interpreting nutrition research, being knowledgeable of emerging food products and concepts, and providing correct information to the public. The widespread lack of clarity and agreement among authorities regarding functional foods, presents a challenge to RDs to fulfill these obligations. Research is deficient regarding RDs' perceived knowledge of functional foods as well as what RDs communicate to their clientele. The purpose of this study is to investigate RDs' perceptions, attitudes and practices concerning functional foods. 


\section{Research Questions:}

Which functional food definition does the majority of RDs believe is correct?

What foods do RDs categorize and define are functional foods?

Does educational level of RDs influence their functional food perceptions, attitudes and practices?

Does the geographic region where RDs practice influence their functional food perceptions, attitudes and practices? 


\section{LITERATURE REVIEW}

Functional foods are applicable in both the health care and food industries. As such, a variety of databases were searched including, CINAHL, Medline, PubMed, Agricola, Ageline and the Health and Wellness Resource Database. The search terms were: functional foods and Registered Dietitians; functional food, knowledge and Registered Dietitians; functional food, attitudes and Registered Dietitians; functional food, perceptions and Registered Dietitians; dietitian and functional food; nutritionist and functional food; complementary alternative medicine and dietitian. It appears a paucity of literature is available regarding functional foods. The search yielded a total of four research articles.

Two of the four peer-reviewed studies surveyed perceived knowledge, attitudes and practices of dietitians regarding functional foods, the third study explored perceived knowledge and opinions, and the fourth study focused exclusively on attitudes. All four were descriptive, cross-sectional studies. Two studies were conducted in the US (Pennsylvania and Oregon), one in Holland and one in Canada.

\section{Oregon Study}

In March 1998, Lee et al. determined the perceived knowledge, attitudes, and practices of licensed dietitians (LDs) regarding functional foods, nutrient supplements, and herbs as complementary medicine (16). A focus group of five dietitians, whose credentials were not specified, developed the survey and devised a definition for functional foods. A geographically stratified, random sample of 202 Oregon LDs was obtained. The source of the sample was not detailed. To qualify as an Oregon LD, an individual must already be a Registered Dietitian. Therefore, the subjects in this study 
were also RDs. The Oregon LD sample was mailed the 21-question survey that included a functional food definition. Eighty percent $(n=162)$ of the sample responded. The majority of LDs were White and 31 - 50 years old. Gender was not reported. Sixty-seven percent $(n=109)$ had bachelor degrees and 32\% $(n=52)$ reported having a master's or doctoral degree. Nearly two-thirds of respondents perceived they had a high level of knowledge about functional foods used to maintain good health and prevent chronic disease. Lee et al. reported $80 \%(n=130)$ of Oregon LDs believed functional foods were safe and effective in maintenance of good health, the prevention of illness and treatment of chronic disease. Eighty-six percent $(n=139)$ reported to personally use functional foods and $94 \%(n=92)$ of LDs employed by a healthcare facility recommended them in the past year.

Although an excellent response rate, the sample was small $(\mathrm{n}=162)$ and only representative of RDs in Oregon. Results could not be generalized to a larger population of RDs. Additionally in Oregon, in order to become an LD, one must be an RD but not all RDs become LDs. Therefore the sample did not represent the views of RDs, only those who became LDs. Also, LDs with master's and doctoral degrees were combined and therefore it was difficult to determine if education influenced the results. Further, gender demographics were not reported. Therefore, it was unclear if the demographics of this sample represented the ADA population.

There were methodological concerns of the content development of the questionnaire. The questionnaire covered three topics that included functional foods, nutrient supplements and herbs. As a result, few questions asked about functional foods and only basic summaries could be made about the knowledge, attitudes and practices of 
RDs regarding functional foods. It would have been more effective to survey RDs on one topic to obtain comprehensive data. In addition, the development of the survey was unclear. Lee et al. stated the five dietitians in the focus group "held professional positions in which they likely had been exposed to questions about complementary dietary therapies" (16). A further explanation of the focus group's background would have given face validity to instrumentation. The functional food definition included in the questionnaire was based on a consensus of the focus group, however no information regarding the definition origin was identified. As this study took place in 1998, and the survey definition did not correspond with the 1995 published ADA definition from the position paper regarding phytochemicals and functional foods, the definition source is unclear. More information on origin of the definition would have given more credibility to the research. As the definition was supplied to LDs on the survey, it is difficult to determine the actual knowledge the LDs had of functional foods. Additionally, the LDs were asked to rate their functional food knowledge on a 1-5 Likert scale with 5 being "very high" and 1 being "none" (16). This was problematic because it did not determine inaccurate or accurate knowledge, only the perception of knowledge LDs thought they had. Further, Lee et al. reported LDs' perceived knowledge however results can only be applied to LDs' perception of the functional food definition supplied, rather than LDs' general perceived knowledge of functional foods.

Although functional food was gaining popularity as an important food topic, it was not until four years later that another American study was conducted. Once again it was conducted in one state, Pennsylvania. 


\section{Pennsylvania Study}

A survey consisting of 64 questions identified the perceived knowledge, attitudes, and self-reported practices of RDs concerning functional foods and herbal medicine (17). The authors reported that a sample of 100 RDs was selected randomly from the Pennsylvania Dietetic Association professional directory. The methodology for selecting the random sample was not discussed. The survey was content-and-face validated by four expert RDs in the areas of functional food and herbal medicine. The experts' qualifications were not reported. The mailed survey included a definition of functional foods and a total of 57 (57\%) surveys were returned. No male RDs completed the survey. The reported ages of RDs ranged from younger than 35 to older than 55 years old, with the majority in the $35-55$ age range. Forty-two percent $(n=24)$ of RDs completed a bachelor's degree, $46 \%(n=26)$ earned a master's degree and 12\% had doctoral degrees. Couch et al. found $98 \%(n=51)$ of RDs thought they should be the authority on functional foods, however $52 \%(n=30)$ did not feel confident in their knowledge of functional food or their qualifications to educate the public $(n=31,54 \%)$. The majority of respondents $(\mathrm{n}=48,84 \%)$ trusted that functional foods could prevent disease and promote health. However only $30 \%(n=17)$ trusted functional food label claims. While $58 \%(n=33)$ claimed to personally use functional foods, only $38 \%(n=22)$ recommended them to clients.

Couch et al. reported the sample was similar to ADA demographics although comparison data with ADA demographics was not provided, but rather the demographic data of respondents to the ADA compensation and benefits survey. In addition, the sample size was small $(n=57)$ so it is difficult to justify how results could represent the 
larger RD population. While the compensation and benefits demographics revealed $4 \%$ $(n=408)$ of the population were male RDs, no males participated in the study. Demographics also revealed an underrepresentation of RDs with bachelor's degrees and an overrepresentation of RDs with masters and doctoral degrees. Therefore, the sample results could not be generalized to the national body of RDs.

The questionnaire development, functional food definition, as well as the perceptions and knowledge results, were debatable. Even though four experts in the functional food and herbal medicine fields validated the survey, Couch et al. did not describe their credentials or the method to validate the instrument. Consequently it is unknown if the experts were qualified or instrument validation methods were appropriate. The source of the definition supplied to participants was not cited. It may have been created for the survey or based on opinion rather than an authentic source. Further, the definition did not coincide with the available ADA definition published in 1999. Having provided a definition to respondents, Couch et al. did not measure perceived knowledge but rather how the participants applied and perceived the definition given. In addition, the survey focused primarily on whole fruits and vegetables, or those foods containing phytochemicals, all of which were considered one subcategory of functional food as outlined by the 1999 ADA position (18).

During the time of the two US studies being conducted, studies were also being developed internationally. The dietitians were being surveyed in Canada and Holland.

\section{Canadian Study}

In 1999, 238 dietitians were contacted from the Dietitians of Canada (DC) membership to determine their attitudes towards functional foods and neutraceuticals 
(19). A panel of 12 randomly chosen dietitians developed and pretested the telephone survey. Potential respondents were mailed a description of the study, possible dates they might be contacted, and the Health Canada (HC) definition of functional foods. Two trained assistants telephoned participants and asked each person to complete a survey consisting of 32 qualitative questions. Sixty-three percent $(\mathrm{n}=151)$ completed the survey. Demographic data reported $53 \%(\mathrm{n}=80)$ of respondents worked in a healthcare setting. Age, sex, race/ethnicity or education level of participants was not reported. Sixty percent ( $n=91)$ of dietitians agreed health claims should be permitted on food products, while $32 \%(n=47)$ disagreed, citing they were difficult for consumers to understand. Sixty-five percent ( $\mathrm{n}=98)$ of participants agreed the public could benefit from functional foods.

Sheeshka et al. suggested the sample of dietitians represented the DC however a comparison was not made between official demographic data of Canadian dietitians and the sample. Further, demographic data was limited as age, ethnicity and education level results were not reported. Therefore, it is unclear if the study sample reflected the larger DC body.

While a random panel of $12 \mathrm{DC}$ members developed and pretested the survey, it would have been more reliable for an independent group to pretest the survey, as panelists were already familiar with the content and questions. Other dietitians' feedback would have contributed to reliable pretesting. The 32 -item questionnaire included the topics of both functional foods and neutraceuticals. Incorporating more than one topic and fewer questions yielded minimal results regarding dietitians' attitudes towards functional foods. Results would have been more valuable had the questionnaire focused on one topic. The survey encompassed qualitative questions, which provided in depth 
subjective data from participants however the quality of data relied on researcher's interpretation of answers. Participants' responses were subject to interpretation at two points during this study; the first time when the trained assistants recorded participant's answers and the second time, when data was coded for analysis. While the results were indicative of Canadian dietitians' attitudes, they could not quantified or generalized to the larger DC population.

The most recent international study was from Holland. Once again it was a national study, which researched dietitians and functional foods.

\section{Holland Study}

In March 2002, a random sample of 500 dietitians from the Dutch Register of Qualified Paramedics was contacted to determine dietitians' opinions about functional foods (20). It is unclear how the random sample was selected. Five nutrition professionals pretested a 62-question survey, which included a definition of functional foods. The mailed survey yielded 238 completed questionnaires for a response rate of $48 \%$. The respondents' ages ranged from under 30 to 65 years old, and ethnicity and education were not reported. Seventy-seven percent $(\mathrm{n}=183)$ of participants worked in the healthcare industry. However this sample was not compared to the national dietetics population. De Jong et al. found that half of the sample $(\mathrm{n}=136,57 \%)$ reported limited functional food knowledge while the other half $(\mathrm{n}=126,53 \%)$ believed they were adequately knowledgeable to counsel clients about functional foods. The majority of dietitians $(\mathrm{n}=164,69 \%)$ ate few or no functional foods however $63 \%(\mathrm{n}=149)$ advised about functional food usage. Dietitians thought functional foods were "useful in specific circumstances," however "specific circumstances" were not described. They also 
indicated that functional foods did not serve any general community interest and again, that was not detailed.

De Jong et al. pretested the survey using five nutrition professionals with credentials ranging from "nutrition scientists to practice dietitians" (20). No other details about the nutrition professionals' expertise or knowledge of functional foods were provided. Additional information would have given credence to the instrument. The questionnaire supplied a working definition however the source of the definition and method for obtaining it were not described. Without knowledge of the definition's origin the interpretation of the results is questionable. De Jong et al. reported results of Dutch dietitians' perceived knowledge of functional foods however in actuality they measured perceived knowledge of the given functional food definition.

\section{Summary of Literature Review}

Four studies exposed a lack of information about dietitians' knowledge and perceptions of functional foods. Holland and Canada have completed national studies with dietitians regarding functional foods however in the US, a national study has not been conducted, the only studies were limited to a particular state (Pennsylvania and Oregon). The US studies did not represent the larger population of RDs of the ADA. Three of the four studies investigated functional foods in addition to herbs or herbal medicine, neutraceuticals and nutrient supplements, and generated broad results. This may have confused participants, as the questionnaires were not focused in the general area of functional foods. A survey that focuses exclusively on functional foods would provide more comprehensive conclusions about RDs perceptions and attitudes of functional foods. Survey development included a panel or focus group to design, pilot or 
validate the questionnaire in each study. However, researchers neglected to specify the credentials of the focus group participants. Such detailed information would make the instrumentation process more reliable. All studies provided a functional food definition to participants however only Sheeshka et al. (Canada) identified the source of their definition. It was difficult to know if the other definitions came from credible sources. Three of the four studies reported dietitians' perceived knowledge however did not indicate perceived knowledge results were limited to the definition provided in the survey. All four studies were completed in 2002 or earlier. While all four studies provided meaningful results, it is still unclear how RDs' define and perceive functional foods.

\section{Conclusion}

To accurately measure dietitians' perceptions of functional food, research would need to encompass all food products and provide multiple definitions from which dietitians could choose. Therefore, the purpose of this study is to investigate US RDs' perceptions, attitudes and practices regarding functional foods. Specifically, what functional food definition RDs' believe is correct, which foods they categorize as functional foods and if education level or geographic region influences their responses. 


\section{METHODOLOGY}

\section{Sample}

A descriptive, cross-sectional study was conducted during the summer of 2009 to investigate RDs' perceptions, attitudes and practices regarding functional foods. Inclusion criteria were RDs who were not retired and resided in the US. Exclusion criteria were Dietetic Technicians Registered, RDs living outside of the US, and those that were retired. The Commission on Dietetic Registration (CDR), the credentialing agency for the American Dietetic Association, provided a random, national sample of 1,800 RDs based on the inclusion criteria. Prospective participants' names, addresses and email addresses were obtained through electronic mail (email). The Institutional Review Board of Florida International University along with CDR approved the study.

\section{Instrument}

The initial instrument was titled, "The Knowledge, Attitudes and Practices of Registered Dietitians' Regarding Functional Foods." Through the feedback of the pilot study and expert panelists, it was determined the variable was perceptions, and not knowledge. Therefore the title of the survey was modified to reflect perceptions, however the content and questions remained the same. The "Perceptions, Attitudes and Practices of Registered Dietitians Regarding Functional Foods" survey was a self-administered questionnaire consisting of 28 questions divided into five sections. Part one focused on perceptions and included three questions; part two examined attitudes about functional foods with seven questions; part three included two questions with an additional three contingency questions related to personal and professional practices; part four asked two 
questions about nutrition information source with one contingency question; and part five collected demographics information through 10 questions (Appendix I).

The instrument was a modification of the two previous US questionnaires. The original survey from Holland was received however as it was written in Dutch, it could not be translated in sufficient time to incorporate into the survey (20). The original Canadian questionnaire was not obtained because access to the article did not occur until after study’s survey was developed (19).

The Couch et al. survey was tested for face validity, and the survey developed by Lee et al. was tested for face and content validity $(16,17)$ (Appendices II and III). Therefore, the current survey was based on previously validated questionnaires. The design, aesthetics and introductory directions were a modification of Couch et al., as well as the question format of the attitudes section, four attitudes questions, five demographics questions, and four self-reported practices questions. One demographic question and one question regarding past behaviors were modified from Lee et al. The remaining 13 questions were developed based on the literature review.

\section{Perceptions Section}

Part one of the questionnaire focused on perceptions and included three questions. Question one asked respondents to choose the best definition for functional foods from a list of six answers. The definitions were chosen to represent the national and international organizations and industries that have varied interests in functional foods. The sources for functional food definitions include ILSINA, FUFOSE, the ADA, the FNB, and the Japanese government. In addition to these five definitions, respondents had a sixth option, "I don't know" for RDs who did not know how to define a functional food. 
The second question determined which food categories RDs thought would be functional foods. Respondents were able to select multiple food categories. The food categories based on the ADA definition included: "fortified products", "enriched products," and "unprocessed or natural products." The other two categories, "herbal supplements" and "dietary supplements," were added from an interpretation of "food components" from the ILSINA definition and "ingredients" from the FNB definition. The "I don't know" option allowed participants to respond if they were unfamiliar with the functional foods. "None of the above" response was included in case participants did not agree with any of the food categories.

In question three, respondents identified foods they thought were functional from a list of 52 items. The foods were divided into eight categories. Six categories were based on the food groups of MyPyramid, grains, meat and beans, fruits, vegetables, milk, oils and fats (21). The other two categories, supplements, and vitamins and minerals, were interpreted from the ILSINA and FNB definitions. "I don't know" was included for RDs who did not know about functional foods. A choice of "other" was also included. If participants chose "other," they had the opportunity to write three foods they thought were functional and were not listed.

\section{Attitudes Section}

The second part initially included eight attitude statements about functional foods. The section was based on a review of literature, the Couch et al. questionnaire, the ADA definition and the ILSINA definition. Each RD rated each attitudinal statement quantitatively based on a five-point Likert scale, 1=strongly agree, $2=$ agree, $3=$ =neutral, 
$4=$ disagree, and $5=$ strongly disagree. This scale specified the extent to which RDs agreed with each statement. The Likert scale was replicated from Couch et al.

Three of the eight attitudinal statements were reviewed and adapted from Couch et al. The first statement, "Functional foods can be used to prevent disease and promote health" was changed to, "Functional foods are effective in preventing disease and promoting health." The Couch et al. statement was interpreted to mean functional foods could generally prevent disease and promote health. The wording in the statement was changed to assert that functional foods produced a result of preventing disease and promoting health. "The use of functional foods improves health" was adapted to read, "Functional foods improve health." The wording of "Functional foods should be integrated into the practice of medicine" was adjusted to "Functional foods should be included as part of a treatment plan for my patients/clients." This statement was reworded to apply to the dietetics practice.

The five remaining attitude statements were based on the ADA and ILSINA definitions, and a literature review of Couch et al. and Lee et al. One attitudinal statement read, "All foods are functional," and was adapted and abbreviated from the ADA definition. "All foods are functional at some physiological level...functional foods that include whole foods and fortified, enriched or enhanced foods have a potentially beneficial effect on health when consumed as part of a varied diet on a regular basis, at effective levels." The fourth statement, "Functional foods provide benefit beyond basic nutrients," was adapted and abbreviated from the ILSINA definition. Functional foods are "those that by virtue of physiologically active food components provide health benefits beyond basic nutrition." The last three statements based on the literature review 
were, "Functional foods are equal to medication," "Herbs should be used as functional foods" and "Whole fruits and vegetables are the only functional foods." The latter statement was removed due to a low reliability score.

\section{Practices Section}

The third part of the survey addressed RDs' personal use of functional foods and professional recommendation to clientele in the past year. Two modified questions were included from Couch et al. and each question had additional contingency questions. The question, "Do you actively include functional foods into your diet in order to maintain or improve health?" was adjusted to, "Do you personally use functional foods?" The question was reworded for simplicity and to determine if RDs in general, personally used functional foods. If RDs responded yes, a contingency question then asked participants to list three functional foods they personally used. The second question from Couch et al. read, "Do you routinely recommend specific functional foods to your clients/patients in order to maintain or improve their health?" It was adapted to read, "Have you recommended functional food(s) to a client/patient in the past year?" This question was also reworded to simplify it and determine if $\mathrm{RDs}$ in general, recommended functional foods to clientele in the past year. If respondents answered yes, two contingency questions followed. The first contingency question asked why RDs had recommended functional foods: "Please indicate for what purpose(s) you have recommended functional food(s)." The answer options for the contingency question were adapted from Lee et al. and read: "maintenance of health"; "prevention of chronic disease"; "treatment of chronic disease"; and "treatment of acute disease." The final contingency question of the attitudes 
section asked RDs to identify three functional foods they had professionally recommended in the previous year.

\section{Nutrition Information Source Section}

Part four was about nutrition information sources and included two adjusted questions from Couch et al. and one contingency question. "Have you had any training to learn more about functional foods?" changed to "Please indicate where you have received your functional food information." Answer options for this question included various sources as well as the option, "I have not received training on functional foods." A question asked if respondents were interested in learning about functional foods. A contingency question from Couch et al. followed: "What is your preferred training or education format for complementary medicine?" The wording was modified to maintain the focus of the study on functional foods and read, "What is your preferred training or education format for learning about functional foods?"

\section{Demographics Section}

The fifth and final part of the survey regarded demographics and asked 10 questions. Four questions were replicated from the Couch et al. survey: "What is your age?"; "What is your gender?"; "What is your current employment status as a Registered Dietitian?"; "Which one of the following describes your work environment?" However, the answer options for the latter question were altered to include "food industry," and "healthcare" changed to "clinical". Two other questions were obtained and adapted from the same survey. The wording of "Which is the highest level of education you have completed?" had slight changes to read, "What is the highest level of education you have 
completed?" One final demographics question was adapted from Lee et al.: "Is your ethnic identity: (followed by 5 options)" to "What is your ethnicity?"

\section{Pilot Study}

The questionnaire was designed to test the knowledge, attitudes and practices of Registered Dietitians regarding functional foods. A pilot test of the questionnaire was conducted at the April 21, 2009 meeting of the Broward Dietetic Association, Fort Lauderdale, FL. Fourteen RDs volunteered to participate in the pilot study to determine face and content validity of the questionnaire. They received the questionnaire plus an additional eight evaluation questions which dealt with the survey's aesthetic appeal; the ease and readability of the survey; suggestions for changing, adding, or deleting any question; content or instructions; and the amount of time it took to complete the survey.

Of the 14 who completed the survey, 12 answered the evaluation questions (Appendix IV); 11 indicated the survey read well; nine would not change or add anything; nine reported the wording to be easy to understand; and 11 thought it was aesthetically appealing. The 12 respondents spent an average of 10 minutes completing the survey. Five participants responded that question one was wordy. In evaluating that feedback, it was determined that abbreviating or summarizing the definitions would alter their meaning since the purpose of the question was to choose a definition. Therefore, no change was made to that question. One participant reported the instructions for question three were unclear. In the instructions for question three, an additional statement was added in bold and capitalized, "you may choose more than one answer in each category."

The challenge to creating an answer key of the knowledge section of the survey was the absence of an official correct response for a definition of functional food, 
functional food categories and functional food products. A panel of experts received the questionnaire via email in order to produce an answer key based on consensus from them of answers to each of the three knowledge questions.

\section{Expert Panel}

The nine expert panelists included an author from each US study, an author from the Holland study (Human Nutritionist for the Centre for Nutrition and Health, National Institute of Public Health and the Environment, the Netherlands), four academics from the Department of Dietetics and Nutrition at Florida International University (FIU) whose courses included the topic of functional foods; an RD employed at the International Food Information Council (IFIC) with previous experience in the development of a national consumer survey regarding functional foods; and an entrepreneurial RD and owner of a functional food company in Miami Dade County, Florida.

The survey, which the expert panelists received, included the original 28 questions, the same eight questions given to pilot study participants and two questions specific for the expert panelists (Appendix V). The panelists were asked to match each definition with associated functional food categories and functional foods to determine a correct answer for assessing knowledge when RDs returned the survey. Of the nine experts contacted, six completed the questionnaire: three FIU professors (two MS, one $\mathrm{PhD}$ ), the RD from IFIC and two US authors from the Pennsylvania and Oregon studies.

Based on the feedback from the expert panel, the ADA definition in question one was changed to reflect the most current definition, which was updated and published in the April 2009 Position of the American Dietetic Association: Functional Foods (5). Another expert panelist suggested changing the instructions of a question that asked RDs 
their preferred training or education format to learn about functional foods. Initially RDs were instructed to select one answer and the question was altered to allow multiple responses.

Three of the expert panelists did not understand the purpose and instructions of the two expert questions and did not complete them. One panelist reported the FNB definition was "too vague" to select associated food categories and foods. The same panelist also asserted that supplements were not foods and did not associate them with any of the definitions. Another panelist did not complete the expert questions, and still another indicated she could not answer the questions at all. Each panelist answered the two expert questions differently and so the results could not be aggregated to form knowledge answers. It was determined that perceptions were being assessed because the accuracy of RDs' responses could not be evaluated. Therefore, the title of the survey was changed to "The Perceptions, Attitudes and Practices of Registered Dietitians Regarding Functional Foods" and replaced the original title, "The Knowledge, Attitudes and Practices of Registered Dietitians Regarding Functional Foods".

Based on pilot test respondents and expert panelists, the reliability and consistency were assessed using the Statistical Package for the Social Sciences for Windows (version 15.0, 2006, SPSS, Inc. Chicago, IL). Cronbach's alphas were calculated for questions two and three (.94), and questions four through $11(.69)$ of the pilot study. When questions four through 11 were analyzed, question seven "Whole fruits and vegetables are the only functional foods," did not fit with the remaining questions. It was removed, thereby raising the Cronbach's alpha score (.79). No reliability measures were calculated for questions 11 through 28 since they had incompatible scales or were 
demographic questions. The interrater reliability of the six experts of the entire questionnaire was .88. At the end of the instrumentation process, the final questionnaire included five sections with 28 questions.

\section{Data Collection}

Data collection occurred from mid-Summer thru mid-Fall 2009. A packet was mailed on July 17, 2009 through the bulk rate mail of the United States Postal Service to each of the 1,800 RDs. The mail packets included a consent form (Appendix VI) describing the study, the questionnaire (Appendix I), and a self-addressed, stamped return envelope. Potential respondents received the typed consent form that indicated an August 3, 2009 deadline to return the survey. However it was realized after materials were printed, bulk mail could take up to two weeks to reach participants. It was thought recipients would discard the questionnaire with a deadline of August 3, 2009. The decided solution was to use a red stamp indicating an extended deadline of August 18, 2009 to give respondents time to return the survey. On July 31, 2009, two weeks after the initial mailing, a postcard was mailed to subjects as a reminder to complete and return the questionnaire.

In response to a large number of invalid mailing addresses, an email was sent to those potential respondents on September 14, 2009 (Appendix VII). The email contained two electronic attachments: an interactive PDF version of the questionnaire and a PDF of the consent form. These participants were asked to complete the questionnaire by September 25, 2009 and were given the option to return the questionnaire through email or US Postal Service at their own expense. Once the survey was returned via email, the document was downloaded and saved with an identifying number to maintain anonymity. 
On September 25, 2009, a reminder email was sent to everyone, with the exception of those who had received the previous email (Appendix VIII). The email excluded those 93 individuals who had previously been contacted on September 14, 2009. If an individual requested another copy of the survey (due to loss or misplacement), the electronic version of the questionnaire and consent form was sent in a follow-up email. It was requested that materials be returned as soon as possible as data collection efforts ceased October 31, 2009.

\section{Statistical Analyses}

The power for the study was determined by G-Power software (Version 3.0.10, 2007, Germany) (22). To obtain 95\% power for the chi-square tests for a medium effect size $(\omega=.3)$ a sample size of 342 was sufficient. The sample size was increased by $10 \%$ (376) to allow for non-responses or incomplete questionnaires.

The data were analyzed with SPSS for Windows (version 15.0, 2006, SPSS, Inc. Chicago, IL). Frequencies and percentages were calculated for all responses to the survey. Chi-square tests were used to compare the responses of participants by education level and by US census practice region. Chi-square goodness-of-fit tests were performed to compare this sample to the national breakdown of gender, education and ethnicity. One-way ANOVAs determined the differences of attitudes in questions $4-10$ by reported education level and by US census region of practice. Tests were statistically significant if $\mathrm{p}<.05$. 


\section{RESULTS}

Of the 1,800 mailed surveys, 390 were returned via USPS $(n=353,91.7 \%)$ and email $(n=32,8 \%)$. Five of the returned surveys were not completed. Therefore 385 surveys were usable resulting in a $22 \%$ response rate.

\section{Demographic Characteristics}

Respondents were from 46 states, which represented all four census regions of the US (Table 1) (23). The majority of respondents were White ( $\mathrm{n}=347,90.1 \%)$, women $(n=368,95.6 \%), 46$ years or older $(n=206,53.5 \%)$, who had earned a master's degree $(n=204,53.1 \%)$ (Table 1). The RDs with PhDs were older (46 - 65 years old) than those with a bachelor's or master's degree (36 - 55 years old). Ninety-five percent of RDs were working. The highest percentage $(41 \%)$ of RDs worked in clinical practice. Many of the RDs who responded lived in either the midwestern $(n=119,32.5 \%)$ or southern $(n=103$, $28.1 \%$ ) regions of the US.

When compared to the national RD population, the sample did not differ significantly for gender $(p=.844)$, ethnicity $(p=.174)$ or US census practice region $(p=.938)$. The education level of the respondents was significantly different than the national sample $(\mathrm{p}<.001)$. The percentage of RDs with a bachelor's degree in this study was $40 \%$, whereas the national population was $96.4 \%$. More RDs had master's degrees $(53.1 \%)$ or doctoral degrees $(6.0 \%)$ than the national population $(2.8 \%$ and $0.7 \%$, respectively).

\section{Perceptions}

Of the five proposed definitions, the ILSINA definition was the most selected $(\mathrm{n}=129,33.5 \%)$ regardless of education level or region where RDs practiced (Tables 
$2,3,4)$. The least selected was the Japanese definition ( $\mathrm{n}=7,1.8 \%)$ (Table 2). For RDs with a bachelor's or master's degree, the second choice for a functional food definition was the FNB (Table 3). The same was true for RDs from the midwestern, southern and western regions of the US (Table 4). Registered Dietitians with doctoral degrees equally selected the FUFOSE and ADA definitions as their second choice.

The majority of RDs chose fortified food products ( $\mathrm{n}=292,75.8 \%)$, enriched food products $(\mathrm{n}=248,64.4 \%)$ and unprocessed, or natural foods $(\mathrm{n}=230,59.7 \%)$ as food categories they perceived to be functional (Figure 1). The least chosen food category was herbal supplements $(\mathrm{n}=72,18.7 \%)$. The RDs' perceptions regarding food categories did not differ signficantly with education level or region of practice.

In terms of individual foods of the 52-food list, the five most selected food items were yogurt with probiotics, eggs with omega-3 fatty acids, olive oil with omega-3 fatty acids, margarine with plant stanols and sterols and orange juice with calcium (Table 5). Eggs with omega-3 fatty acids were the most chosen by RDs with doctoral degrees whereas participants with a bachelor's or master's degree chose yogurt with probiotics. However RDs from all four regions identified yogurt with probiotics the most.

In the grains group, the majority of participants selected old fashioned oatmeal $(\mathrm{n}=258,67.0 \%)$ (Table 5). Approximately 10 times more RDs chose a chocolate chip cookie with fiber $(\mathrm{n}=218,56.6 \%)$ than the regular chocolate cookie $(\mathrm{n}=21,5.7 \%)$ or lowfat chocolate chip cookie ( $\mathrm{n}=28,7.3 \%)$. Fewer RDs chose low-calorie bread $(\mathrm{n}=38,9.9 \%)$ than multigrain bread $(\mathrm{n}=207,53.8 \%)$.

Salmon ( $\mathrm{n}=239,62.1 \%$ ) was identified as a functional food by more $\mathrm{RDs}$ than any other animal protein (Table 5). Less than $20 \%$ of RDs selected chicken ( $\mathrm{n}=75,19.5 \%)$ or 
ground beef $(n=64,16.6 \%)$ and the least chosen item of the meat and beans group was ground beef.

In the fruit group, fortified juices were chosen more than non-fortified juices (Table 5). However respondents chose cranberry juice $(\mathrm{n}=193,50.1 \%)$ and cranberry juice with pomegranate $(\mathrm{n}=225,58.4 \%)$ equally. Of the tomato food products, RDs preferred ketchup $(\mathrm{n}=78,20.3 \%)$ less than tomatoes $(\mathrm{n}=215,55.8 \%)$.

Registered Dietitians viewed soybean products and soybeans similarly and were chosen the most out of all the vegetables. Half of the respondents thought avocados $(\mathrm{n}=194,50.4 \%)$ were a functional food however only $30 \%$ perceived guacamole $(\mathrm{n}=119$, $30.9 \%)$ as a functional food.

Of the six available options in the fat and oil, and milk groups, the fortified food products were selected by the most RDs. Approximately 35\% more dietitians identified olive oil with omega-3 fatty acids $(\mathrm{n}=315,81.8 \%)$ as a functional food than regular olive oil $(\mathrm{n}=184,47.8 \%)$. Margarine with plant stanols and sterols was selected 10 times more than regular margarine. Yogurt with probiotics was also chosen as a functional food by $50 \%$ more RDs than regular yogurt.

In the supplements category flaxseed oil and fish oil were identified by nearly half of participants as functional foods (Table 6). All five vitamins and minerals were selected by less than $35 \%$ of RDs.

Of the 52-food list, RDs with a bachelor's ( $\mathrm{n}=140,89.2 \%)$ or a master's ( $\mathrm{n}=179$, 87.7\%) degree identified yogurt with probiotics the most as a functional food while RDs with doctoral degrees $(\mathrm{n}=20,87.0 \%)$ selected eggs with omega 3 fatty acids. Yogurt with 
probiotics was also identified the most by RDs in the northeast ( $\mathrm{n}=69,85.2 \%)$, midwest $(n=102,85.7 \%)$, south $(n=93,90.3 \%)$ and western $(n=56,88.9 \%)$ regions of the US.

\section{Attitudes}

When agreed and strongly agreed were aggregated, nearly $75 \%(n=282,73.2 \%)$ of RDs regarded functional foods as effective in disease prevention and health promotion (Figure 2). Registered Dietitians did not accept all foods as functional foods, with nearly $25 \%$ who were neutral and over $40 \%$ who disagreed or strongly disagreed with the statement (Figure 3). The majority of RDs $(n=311,80.8 \%)$ concurred that functional foods improve health with only $3.1 \%(n=12)$ who disagreed and none that strongly disagreed (Figure 4). Less than $5 \%(n=12,3.1 \%)$ of dietitians did not agree that functional food provided benefit beyond basic nutrients, and less than $15 \%$ were neutral (Figure 5). Over $60 \%$ of RDs concurred that functional foods should be a part of patient/client's treatment plans (Figure 6). Nearly half of RDs disagreed $(n=140,36.4 \%)$ or strongly disagreed $(n=51,13.2 \%)$ that functional foods were equal to medication (Figure 7). Registered Dietitians were either neutral ( $n=160,41.6 \%)$ or disagreed $(n=145$, $37.7 \%$ ) that herbs were functional foods (Figure 8).

A significantly lower percent of RDs with doctoral degrees agreed that, functional foods should be a part of treatment plans for patients $(\mathrm{p}<.004)$ (Table 7). A significantly less percent of RDs from the northeast agreed that functional foods improve health $(\mathrm{p}=.002)$ (Table 8$)$. The percent of RDs from the northeast $(\mathrm{n}=51,64.5 \%)$ who agreed that functional foods improve health, was significantly less than those RDs from the midwest $(n=87,74.4 \%)$, south $(n=73,72.3 \%)$ and western $(n=45,75.0 \%)$ regions $(\mathrm{p}<.001)$ 


\section{Practices}

Three-quarters of RDs personally used functional foods and over half professionally recommended them to clients in the past year (Table 9). Registered Dietitians who earned a master's degree $(n=161,79.7 \%)$ personally used functional foods more than RDs with bachelor's degrees $(n=114,73.1 \%)$ or $\operatorname{PhD}$ RDs $(n=14,60.9 \%)$. Fewer PhD RDs ( $\mathrm{n}=8,36.4 \%)$ had professionally recommended functional foods in the past year than those with a master's $(n=127,63.8 \%)$ or bachelor's degree $(n=96,62.3 \%)$. With regards to the region of practice, personal use and professional recommendation were similar among dietitians.

When asked which functional food they specifically consumed, fruit $(n=138$, $48.4 \%)$ was identified the most (Table 10). Yogurt products $(n=77,20.0 \%)$ were the most professionally recommended to clientele in the past year. The written responses for each question regarding functional foods personally used and professionally recommended were categorized into similar food products. For example, blueberries, apples and oranges were recognized as fruit. Kefir, regular yogurt and yogurt with probiotics were identified as yogurt products.

Of the four reasons for recommending a functional food to clientele, maintenance of good health ( $\mathrm{n}=175,45.5 \%)$ was predominant (Table 11). The PhD RDs $(n=2,8.7 \%)$ recommended functional foods to treat chronic disease significantly less than those with a master's degree $(n=72,35.3 \%)$ or bachelor's degree $(n=49,31.2 \%),(p=.033)$ (Table 12). Region of practice did not influence dietitians' purpose for recommending functional foods to clientele (Table 13). 


\section{Nutrition Information Source}

Registered Dietitians mainly received their information from attending a professional conference $(\mathrm{n}=115,29.9 \%)$ (Table 14$)$. Over $25 \%$ did not receive training about functional foods $(\mathrm{n}=104,27.0 \%)$. One hundred and eight $(28 \%)$ respondents learned of functional foods from a peer-reviewed journal and 78 (72\%) of those identified another source. Sixty-six (85\%) of the 78 indicated the Journal of the American Dietetic Association as their journal source. Of those 78 , only 14 (21.2\%) chose the ADA definition as the best definition of functional food.

The majority of RDs ( $\mathrm{n}=353,92.9 \%)$ indicated an interest in learning about functional foods. Registered Dietitians did not prefer a specific format to learn about functional foods (Figure 9). 


\section{DISCUSSION}

Functional foods are an emerging industry and controversial topic however it is clear definition what constitutes a functional food $(4,5,6,7,8,9)$. Food and nutrition authorities have different perspectives and missions that have guided the development of their definition for functional foods. Few studies have explored RDs' understanding of functional foods $(16,17,18,19)$. This study investigated RDs' perceptions, attitudes and practices regarding functional foods and currently it seems there are inconsistencies among RDs about functional foods.

\section{Demographics}

The sample represented the national population. The majority of respondents were White women, 46 years or older and had earned a bachelor's or master's degree. Over $40 \%$ of dietitians were employed in a clinical setting and $60 \%$ practiced in the midwest and southern regions. A smaller percentage practiced in the northeast and western regions, however when demographics were compared to self-reported data from CDR, the sample represented the national population regarding US census region of practice, gender and ethnicity. However there were differences among educational levels. Registered Dietitians with bachelor's degrees (40.9\%) were under-represented in this sample compared to $96.4 \%$ in the CDR population. Registered Dietitians with master's $(53.1 \%)$ and doctoral degrees $(6.0 \%)$ were over-represented compared to the national population, $2.8 \%$ and $0.7 \%$, respectively. Couch et al. found similar results (17). It is possible a larger number of RDs with graduate degrees responded because the survey indicated it was for the thesis research of a master's student. Additionally, most of the PhD RDs worked in an educational institution and likely oversaw research for master's 
students. Respondents may have empathized and understood the importance of a high response rate. Regardless of educational level, nearly $75 \%$ of RDs had not previously learned about functional foods. Therefore, those RDs who responded may have been interested in learning about functional foods. This finding is reasonable since functional foods were conceptualized in the early 1990s, and the majority of participants were over 45 years of age $(1,2,3)$.

\section{Perceptions}

Previous research studied dietitians' understanding of functional foods, however provided one definition at the beginning of the questionnaire $(16,17,19,20)$. The definitions were based on the perceptions of the focus groups, not food and nutrition authorities. Therefore, this limited the results because the definition was not officially sanctioned. The current study differentiated itself by providing a variety of definitions from food and nutrition authorities to respondents, and then asked them to choose the definition that best defined a functional food.

Results revealed there was no consensus among RDs about a functional food definition. While RDs preferred the ILSINA definition, there were minimal differences between definitions (Table 2). Therefore it is not possible to make conclusions about how RDs define functional foods although it does demonstrate the variety of perceptions held by RDs. The inherent "wordiness" of the definition question may have contributed to the first definition (ILSINA) being selected the most as Fowler pointed out, a wordy question is difficult for respondents to complete (24). The Japanese definition was perceived as the least plausible functional food definition. When responses were analyzed according to education degree or region of practice, there was no difference within each definition. 
Therefore, the degree and region of practice did not appear to influence the choice of definition.

The majority of RDs considered fortified food products, enriched food products and unprocessed or natural food products to be functional foods. Fewer dietitians chose both dietary and herbal supplements. Thus RDs considered foods, and not supplements, as functional foods. This notion coincides with dietitians' underlying principle that the "best nutrition-based strategy" to maintain health, results from getting nutrients from food rather than supplements $(25,26)$. Although RDs chose the three food categories reflected in the ADA definition, fewer RDs chose the actual ADA definition. Rather, RDs selected the ILSINA definition, which used non-specific language and did not specify food categories but mentioned "food components."

When RDs were asked to choose which foods were functional from a list of 52 different foods, they selected fortified foods more than other foods. This finding supports RDs' choice of fortified food products as a functional food category. Registered Dietitians consistently chose fortified foods. Of the ten most selected functional foods, six of them were fortified and the remaining four were whole or unprocessed foods. Unfortunately enriched foods were not included in the survey and so it cannot be determined if dietitians would have chosen them.

The three most identified functional foods in the grains group were old-fashioned oatmeal, multigrain bread and the chocolate chip cookie with fiber. Dietitians also selected the chocolate chip cookie with fiber more than the other types of chocolate chip cookies. The low-fat chocolate chip cookie and regular chocolate chip cookie were chosen equally, by less than a tenth of RDs. Multigrain bread was chosen five times more 
by dietitians than the low-calorie bread. Of the hot cereals, old-fashioned oatmeal was selected by twice as many RDs than were instant oatmeal and three times more than cream of wheat. The chocolate chip cookie with fiber, old-fashioned oatmeal and multigrain bread all provide fiber, which has been associated with improving bowel function and lowering the risk for cardiovascular disease risk, cancer and diabetes (27). Therefore, it seems dietitians perceived foods with added components, specifically fiber, as functional foods although they did not view a food with lower fat or kilocalorie content as a functional food.

Close to two-thirds of RDs considered salmon as a functional food. Salmon was also the most selected food of the flesh protein options. Eggs with omega-3 fatty acids were chosen by RDs three times more than regular eggs and were the most identified functional food in the meat and beans group. Both foods are naturally or fortified with omega-3 fatty acids and it could be the majority of RDs considered them functional foods because research which has indicated omega-3 fatty acids may lower heart disease and stroke risk $(28,29)$. Also, the selection of salmon and eggs with omega-3 fatty acids correspond with dietitians' perception of fortified and whole or unprocessed foods as functional foods. Ground beef was perceived as the least functional food and this might be credited to the numerous public health alerts and reports foodborne illness in the past few years (30).

In the fruit group, less than a quarter of RDs considered ketchup as a functional food while over half of participants perceived a tomato as a functional food. Registered Dietitians also chose fortified fruit juices more than non-fortified juices. Further, orange juice with calcium was selected slightly more than blueberries, and identified by the most 
dietitians as a functional food in the fruit group. These findings were previously indicated when RDs' selected fortified food products more than whole or unprocessed food products. Therefore, it is reasonable that blueberries were selected less than orange juice with calcium, and that tomatoes were selected more than ketchup, as it is a processed food product. It was thought RDs would select ketchup and tomatoes similarly as both contain lycopene, the bioactive compound associated with lowering risk of cancer and cardiovascular disease $(31,32)$. Ketchup bottles even advertise lycopene, however other studies have indicated dietitians do not trust or believe functional food claims $(17,19)$.

When avocados were compared with guacamole, avocados were identified by more RDs as a functional food. Soybeans were selected by more RDs than soybean products and were the most selected functional food in the vegetable group. These findings coincide with RDs' perceptions of whole or unprocessed foods as more functional than processed items. Interestingly, PhD RDs selected soybeans and soybean products $10 \%$ more than RDs with bachelors and master's degrees. Soybeans and soybean products are commonly used to treat peri and post-menopausal symptoms $(33,34)$. Since PhDs were in an age bracket closer to menopausal age, the difference in perceptions is reasonable.

In the oils and fats group, a large difference in perception was found between regular margarine and margarine with plant stanols and sterols. The same was true for regular olive oil and olive oil with omega-3 fatty acids. More dietitians selected the food products with added components, plant stanols and sterols, and omega-3 fatty acids, than the non-fortified food products. Registered Dietitians again affirmed their perception that fortified food products are functional foods. The products appeal increased with the 
addition of the components, which likely relates to their associated health benefits. Research has shown the addition of plant stanols and sterols into the diet can lower lowdensity lipoprotein cholesterol levels, and omega-3 fatty acids have been linked to lower risk of cardiovascular disease and stroke $(27,28,35,36)$.

Of the two food products in the milk group, twice as many dietitians selected yogurt with probiotics than regular yogurt. Yogurt with probiotics was also the single most selected functional food from the 52-item food list. The addition of probiotics increased the perceived value of yogurt, which may relate to the claims to improve “intestinal integrity" (37,38). This finding maintains RDs identified fortified food products as functional foods.

Fewer RDs selected fish oil than salmon, a fatty fish with naturally occurring fish oil. Both items contain omega-3 fatty acids. A glucosamine supplement was chosen by just over $20 \%$, whereas orange juice with added glucosamine was selected three times more by RDs as a functional food. Almost half of the dietitians chose dietary fiber as a functional food whereas old-fashioned oatmeal, which has a high fiber content, was selected by over $65 \%$ of RDs. Foods were selected more than supplements, which probably results from RDs' belief that it is more healthful to receive nutrients from foods than through supplementation $(25,26)$. Therefore, RDs perceived foods as more functional than supplements.

Few differences were found among dietitians' selection of vitamins and minerals. Calcium and vitamin D was chosen most however the other vitamin and mineral options were selected similarly by RDs. Therefore, dietitians perceived the five vitamins and 
minerals equally as functional foods, and reiterates RDs' preference for food over supplements.

While RDs did not reach a consensus regarding a functional food definition, results repeatedly support RDs' perception of fortified foods as functional foods. Respondents identified fortified food products more than other food categories, and RDs' responses to the 52-food list confirmed fortified foods were perceived as functional foods. Furthermore, fortified foods were perceived to be more functional than nonfortified foods, and foods were selected more as functional foods than supplements, including vitamins or minerals.

\section{Attitudes}

Nearly three-quarters of respondents strongly agreed or agreed that "Functional foods are effective in preventing disease and promoting health" and no respondents strongly disagreed. A similar statement read, "Functional foods improve health" and as thought, RDs responded similarly with close to $70 \%$ who strongly agreed or agreed. Other research has shown dietitians agree with similar attitudinal statements $(16,17)$. The ADA describes RDs as "the professionals who are trained to help people achieve health by 'eating right"' (38). It could be that RDs agreed with both statements because each identified the fundamental relationship between food and health. The majority of RDs strongly agreed or agreed that functional foods should be included as part of a treatment plan for clientele, and this is reasonable since RDs agreed functional foods improved and promoted health, and prevented disease. However this conclusion cannot be entirely true because it assumes RDs would agree all foods to be functional. On the contrary, nearly half of dietitians strongly disagreed or disagreed that all foods were functional. There is 
an inconsistency in RDs' responses because this last statement had similar phrasing to the ADA definition, which was chosen by less than $20 \%$ of RDs. Although when RDs identified functional food categories, they selected the three food categories listed within the ADA definition. This finding may again result from the wordy nature of the definition question. Just over $80 \%$ of dietitians strongly agreed or agreed, "Functional foods provide benefit beyond basic nutrients." This response was expected as the attitudinal statement exhibited similar language to the ILSINA definition, which was the most selected functional food definition by dietitians. Registered Dietitians agreed less with the statement, "Functional foods are equal to medication." While food is viewed as the body's medicine in some cultures, there is a strong line of delineation between food and medicine in the US (8). Registered Dietitians support the use of food to maintain a healthy lifestyle and medication, by the US standards, is outside the scope of dietetics $(25,26,39)$. "Herbs should be used as functional foods" yielded a similar response, which corresponds with fewer RDs selection of herbal supplements in the 52-food list.

Educational level and region of practice did not yield significant differences in responses. Although $\mathrm{PhD}$ RDs agreed less that functional foods should be included as part of a treatment plan for patients/clients. This may relate to the majority of $\mathrm{PhD} \mathrm{RDs}$ working in an education institution and not working in a counseling capacity to recommend functional foods.

Registered Dietitians were more likely to agree with statements that dealt with functional foods and their relationship to health, as opposed to statements regarding functional foods and medication or herbs. This may again result from dietitians supporting food to maintain a healthy lifestyle (38). 


\section{Practices}

Over three-quarters of the respondents personally used functional foods in their diet, while closer to $60 \%$ professionally recommended them to clientele in the past year. Couch et al. reported similar findings with 58\% who personally used functional foods and less than $30 \%$ of the RDs who recommended them (17). While the difference between personal use and professional recommendation by RDs was not explored in this study, it could have been RDs were not confident in their knowledge of functional food as Couch et al. found, or that there was inadequate proof of functional foods' efficacy as de Jong et al. found $(17,20)$.

It was thought RDs from the western region would personally use and professionally recommend functional foods more than other regions, however all regions responded in the same way; more RDs personally used functional foods than professionally recommended them. Lee et al. found the majority of dietitians in Oregon used functional foods and a higher percentage professionally recommended them (16). It was suggested dietitians accepted functional foods more in Oregon because naturopathic doctors were legal in state and dietitians were more accustomed to alternative therapies. Educational level revealed fewer $\mathrm{PhD}$ RDs personally ate or professionally recommended functional foods in the past year, than RDs with a master's degree or bachelor's degree. This may result from $\mathrm{PhD}$ RDs being older than other RDs in the sample, the least likely to have learned about functional foods in university and the most likely to work in an education institution where counseling may not be a part of their occupation.

Yogurt products were the most professionally recommended food in the past year was yogurt products. The most selected functional food of the 52 -food list was also a 
yogurt product, yogurt with probiotics. These findings are consistent with other studies that found yogurt as the most accepted functional food $(1,12,40,41)$. Registered Dietitians identified whole fruit as the most personally used functional food. Yet in the perceptions section, RDs selected fortified juices more than whole fruit. It could be that RDs understand functional foods to be fortified food products but not necessarily trust that those fortified products are healthier than whole fruits. Nearly half of RDs indicated "maintenance of good health" as their purpose for professionally recommending functional foods to clientele in the past year. This likely relates again to RDs' description as the health professionals who help others achieve optimal health by "eating right" (38).

Results of RDs' practices demonstrate that the majority of dietitians personally used functional foods. Fewer RDs had professionally recommended them in the past year and if they did, it was mainly for "maintenance of good health." This finding probably indicates RDs lack of confidence in functional foods or possibly a lack of confidence in their personal knowledge of functional foods as Couch et al. found (17).

\section{Nutrition Information Source}

A professional conference was identified as the predominant functional food information source, followed by a peer-reviewed journal. Seventeen percent $(n=66)$ of respondents learned about functional foods from the Journal of the American Dietetic Association (JADA). Interestingly, less than a quarter of those 66 selected the ADA definition. Further, among those who identified learning about functional foods from a journal, no significant differences were found between those who cited JADA, another

journal, or did not provide a journal title. Therefore there was no difference if a respondent had learned about functional foods from JADA or another peer-reviewed 
journal in selecting a functional food definition. Although less than $30 \%$ did not have previous training on functional foods, more than $90 \%$ of RDs responded they would like to learn more. Other studies have yielded similar results $(16,17,20)$.

\section{Research Questions}

Which functional food definition does the majority of RDs believe is correct? A majority of RDs did not select any one functional food definition. The ILSINA definition was selected by a third of dietitians.

What foods do RDs categorize and define are functional foods? Over threequarters of RDs identified fortified foods as functional foods among the five food categories. This finding was confirmed again with results of the 52-food list. The five most selected functional foods were all fortified foods and were chosen by nearly $75 \%$ of RDs.

Does educational level of RDs influence their functional food perceptions, attitudes and practices? Education level did not yield major differences in the way the sample of RDs responded to questions. Registered Dietitians' perceptions of functional foods were similar regardless of education level. Two statically significant differences were found among attitudes, practices and education level. Registered Dietitians with doctoral degrees agreed less that functional foods should be a part of treatment for patients/clients $(\mathrm{p}<.004)$, and $\mathrm{PhD} \mathrm{RDs}$ also recommended them less to clientele $(\mathrm{p}=.003)$.

Does the geographic region where RDs practice influence their functional food perceptions, attitudes and practices? Region of practice influenced RDs' perceptions, attitudes and practices less than education level. No statistically significant differences 
were identified among region of practice and RDs' perceptions or practices regarding functional foods. Only one significant difference was found among attitudes and region of practice. The northeastern region agreed less that functional foods improve health $(\mathrm{p}<.05)$.

\section{Limitations}

The current study obtained a $22 \%(n=385)$ response rate and determined RDs' perceptions, attitudes and practices of functional foods. Other comparable studies achieved $48 \%(\mathrm{n}=238), 57 \%(\mathrm{n}=57), 63 \%(\mathrm{n}=151)$, and $86 \%(\mathrm{n}=162)$ response rates $(16,17,19,20)$. A few possibilities might have altered the number of responses. The initial mailing was sent out during the summer, when many professionals are on vacation. Registered Dietitians may have opened the survey after the return deadline and discarded it. Several factors affected email communication: subjects were not notified prior to the email; they may have regarded it as junk mail and ignored it; the email may have been distributed to the recipient's spam box; or the intended recipient received it after the proposed deadline and disregarded it. A greater response rate might have been acquired if the instrument was mailed during another time of year, a notice of a future email correspondence was communicated to prospective participants, or an incentive offered for the completion of the survey.

The 52-item food list in the survey instrument was limited as a few of the food groups contained an inadequate number of items. This was true for the milk group, which included only two products, as well as oils and fats, which had four items. However the reason for the limited number of items within the 52-food list was to limit the length of the questionnaire as well as the number of foods within the food list. In the fruit group, 
two out of the eight options were whole fruits. It would have been more effective to offer more of a variety of foods within each category. In addition, food categories between questions two and three were inconsistent. The 52-item list did not include enriched products. Results would have been strengthened had enriched food products been included as it was a potential functional food category in question two. Dietary supplements and herbal supplements were also listed as potential functional food categories, however in the 52-item list of question three, supplements, and vitamins and minerals, were the only available groups. It would have been more valuable to differentiate between dietary supplements and herbal supplements in question three.

\section{Recommendations}

Recommendations to advance RDs' understanding of functional foods are many. It would be beneficial to offer web course for continuing professional education credits (CPE) to enable learning about functional foods from home. The ADA could offer a session about functional foods at the annual Food and Nutrition Conference and Expo. The Commission on Accreditation for Dietetics Education could require an education component for foundation knowledge within the didactic curriculum content. Being that the ADA is the "world's largest organization of food and nutrition professionals," it would be ideal to lead the collaboration with other food and nutrition authorities to gain a consensus of a functional food definition (39).

\section{Future Research}

Future research opportunities might involve a web-based survey with close-ended and open-ended questions. Further, one might test the knowledge of RDs and focus on 
the lack of a universal definition, FDA regulations, functional food labeling and/or the food industry's intentions with marketing and nutrigenomics.

\section{Conclusion}

Registered Dietitians revealed inconsistencies between their perceptions, attitudes and practices regarding functional foods. This indicates a need for professional education and training. While dietitians lacked agreement on a functional food definition, they consistently identified fortified foods as functional foods. Registered Dietitians agreed functional foods should be a part of a treatment plan for clientele, yet more RDs personally used functional foods than professionally recommended them. These findings

probably indicate that RDs are uncertain of functional foods, which can be attributed to the lack of a universal functional food definition among food and nutrition authorities. This presents a significant challenge for RDs to gain knowledge and provide accurate information to the public. Even though functional foods are an ill-defined term, RDs are the nutrition experts and must be knowledgeable and cognizant of the issues surrounding them as their popularity continues to rise, parallel to healthcare costs (4). 
Table 1. Demographic characteristics of respondents who completed a national survey: perceptions, attitudes and practices of Registered Dietitians regarding functional foods $(\mathrm{n}=385)$

\begin{tabular}{|c|c|c|c|}
\hline Demographics & & $\mathrm{n}$ & $\%$ \\
\hline \multirow[t]{7}{*}{ Age } & 25 and younger & 14 & $3.6 \%$ \\
\hline & $26-35$ years old & 85 & $22.1 \%$ \\
\hline & $36-45$ years old & 77 & $20.0 \%$ \\
\hline & $46-55$ years old & 127 & $33.0 \%$ \\
\hline & $56-65$ years old & 69 & $17.9 \%$ \\
\hline & $66+$ years old & 10 & $2.6 \%$ \\
\hline & No Answer & 3 & $0.8 \%$ \\
\hline \multirow[t]{3}{*}{ Gender } & Women & 368 & $95.6 \%$ \\
\hline & Men & 14 & $3.7 \%$ \\
\hline & No Answer & 3 & $0.8 \%$ \\
\hline \multirow[t]{4}{*}{ Education Level } & Bachelor's Degree & 157 & $40.9 \%$ \\
\hline & Master's Degree & 204 & $53.1 \%$ \\
\hline & Doctoral Degree & 23 & $6.0 \%$ \\
\hline & No Answer & 1 & $0.3 \%$ \\
\hline \multirow[t]{6}{*}{ Race/Ethnicity } & Asian/Pacific Islander & 13 & $3.4 \%$ \\
\hline & Black/African American & 8 & $2.1 \%$ \\
\hline & Hispanic/Latino & 9 & $2.3 \%$ \\
\hline & White/Caucasian & 347 & $90.1 \%$ \\
\hline & Other & 3 & $0.8 \%$ \\
\hline & No Answer & 5 & $1.3 \%$ \\
\hline Employment & Full Time (40 hrs $\leq$ per wk) & 210 & $54.5 \%$ \\
\hline \multirow[t]{4}{*}{ Status } & Part Time $(<40$ hrs per wk $)$ & 117 & $30.4 \%$ \\
\hline & Unemployed & 11 & $2.9 \%$ \\
\hline & Not Currently Working as an RD & 39 & $10.1 \%$ \\
\hline & No Answer & 8 & $2.1 \%$ \\
\hline Work & Community-Based Organization & 46 & $11.9 \%$ \\
\hline \multirow[t]{7}{*}{ Environment } & Education Institution & 35 & $9.1 \%$ \\
\hline & Clinical & 160 & $41.6 \%$ \\
\hline & Private Practice & 31 & $8.1 \%$ \\
\hline & Government & 30 & $7.8 \%$ \\
\hline & Food Industry & 8 & $2.1 \%$ \\
\hline & Other & 56 & $14.5 \%$ \\
\hline & No Answer & 19 & $4.9 \%$ \\
\hline \multirow[t]{5}{*}{ Practice Region ${ }^{\mathrm{a}}$} & Northeast & 81 & $22.1 \%$ \\
\hline & Midwest & 119 & $32.5 \%$ \\
\hline & South & 103 & $28.1 \%$ \\
\hline & West & 63 & $17.2 \%$ \\
\hline & No Answer & 19 & $4.9 \%$ \\
\hline
\end{tabular}

${ }^{\text {a }}$ Based on Census Region and Divisions of the United States 
Table 2. Registered Dietitians who either selected one of five functional food definitions or "I don't know"

\begin{tabular}{|c|c|c|c|}
\hline Organization & Definition & n & $\%$ \\
\hline $\begin{array}{l}\text { International Life } \\
\text { Sciences of North } \\
\text { America } \\
\text { (ILSINA) }\end{array}$ & $\begin{array}{l}\text { Functional foods are "those that by virtue of } \\
\text { physiologically active food components provide } \\
\text { health benefits beyond basic nutrition." }\end{array}$ & 129 & $33.5 \%$ \\
\hline $\begin{array}{l}\text { Food and } \\
\text { Nutrition Board - } \\
\text { Institute of } \\
\text { Medicine (FNB) }\end{array}$ & $\begin{array}{l}\text { Functional foods are "those foods that encompass } \\
\text { potentially healthful products including any } \\
\text { modified food or ingredient that may provide a } \\
\text { health benefit beyond the traditional nutrients it } \\
\text { contains." }\end{array}$ & 86 & $22.3 \%$ \\
\hline $\begin{array}{l}\text { Functional Food } \\
\text { Science in Europe } \\
\text { (FUFOSE) }\end{array}$ & $\begin{array}{l}\text { Functional foods are those that have "satisfactorily } \\
\text { demonstrated to affect beneficially one or more } \\
\text { target functions in the body, beyond adequate } \\
\text { nutritional effects in a way that is relevant to } \\
\text { either an improved state of health and well-being } \\
\text { and/or reduction of risk of disease." }\end{array}$ & 69 & $17.9 \%$ \\
\hline $\begin{array}{l}\text { American Dietetic } \\
\text { Association } \\
(\text { ADA) }\end{array}$ & $\begin{array}{l}\text { "All foods are functional at some physiological } \\
\text { level...functional foods that include whole foods } \\
\text { and fortified, enriched or enhanced foods have a } \\
\text { potentially beneficial effect on health when } \\
\text { consumed as part of a varied diet on a regular } \\
\text { basis, at effective levels." }\end{array}$ & 68 & $17.7 \%$ \\
\hline I don't know & & 26 & $6.8 \%$ \\
\hline $\begin{array}{l}\text { Government of } \\
\text { Japan }\end{array}$ & $\begin{array}{l}\text { Foods that are "composed of functional } \\
\text { ingredients that affect the structure and/or function } \\
\text { of the body and are used to maintain or regulate } \\
\text { specific health conditions." }\end{array}$ & 7 & $1.8 \%$ \\
\hline
\end{tabular}


Table 3. Definition choices of Registered Dietitians according to their education

\begin{tabular}{lcccccc}
\hline Organization & \multicolumn{2}{c}{ Bachelors } & \multicolumn{2}{c}{ Masters } & \multicolumn{2}{c}{ Doctoral } \\
& $\mathrm{n}$ & $\%$ & $\mathrm{n}$ & $\%$ & $\mathrm{n}$ & $\%$ \\
\hline & 58 & $36.9 \%$ & 65 & $31.9 \%$ & 6 & $26.1 \%$ \\
\hline $\begin{array}{l}\text { International Life Sciences of North } \\
\text { America (ILSINA) }\end{array}$ & 27 & $17.2 \%$ & 37 & $18.1 \%$ & 5 & $21.7 \%$ \\
\hline $\begin{array}{l}\text { Functional Food Science in Europe } \\
\text { (FUFOSE) }\end{array}$ & 32 & $20.4 \%$ & 49 & $24.0 \%$ & 4 & $17.4 \%$ \\
\hline $\begin{array}{l}\text { Food and Nutrition Board - Institute } \\
\text { of Medicine (FNB) }\end{array}$ & 26 & $16.6 \%$ & 37 & $18.1 \%$ & 5 & $21.7 \%$ \\
\hline $\begin{array}{l}\text { American Dietetic Association } \\
\text { (ADA) }\end{array}$ & 4 & $2.5 \%$ & 3 & $1.5 \%$ & 0 & $0 \%$ \\
\hline Government of Japan & 10 & $6.4 \%$ & 13 & $6.4 \%$ & 3 & $13.0 \%$ \\
\hline I don't know & & & & &
\end{tabular}

Table 4. Definition choices of Registered Dietitians based on the region where they practiced ${ }^{\text {a }}$

\begin{tabular}{lcccccccc}
\hline Organization & \multicolumn{2}{c}{ Northeast } & \multicolumn{2}{c}{ Midwest } & \multicolumn{2}{c}{ South } & \multicolumn{2}{c}{ West } \\
& $\mathrm{n}$ & $\%$ & $\mathrm{n}$ & $\%$ & $\mathrm{n}$ & $\%$ & $\mathrm{n}$ & $\%$ \\
\hline & 23 & $28.4 \%$ & 43 & $36.1 \%$ & 33 & $32.0 \%$ & 22 & $34.9 \%$ \\
\hline $\begin{array}{l}\text { International Life } \\
\begin{array}{l}\text { Sciences of North } \\
\text { America (ILSINA) }\end{array}\end{array}$ & 19 & $23.5 \%$ & 20 & $16.8 \%$ & 20 & $19.4 \%$ & 9 & $14.3 \%$ \\
\hline $\begin{array}{l}\text { Functional Food } \\
\begin{array}{l}\text { Science in Europe } \\
\text { (FUFOSE) }\end{array}\end{array}$ & 16 & $19.8 \%$ & 24 & $20.2 \%$ & 25 & $24.3 \%$ & 15 & $23.8 \%$ \\
\hline $\begin{array}{l}\text { Food and Nutrition } \\
\text { Board - Institute of } \\
\text { Medicine (FNB) }\end{array}$ & 18 & $22.2 \%$ & 22 & $18.5 \%$ & 14 & $13.6 \%$ & 12 & $19.0 \%$ \\
\hline $\begin{array}{l}\text { American Dietetic } \\
\text { Association (ADA) }\end{array}$ & 0 & $0 \%$ & 3 & $2.5 \%$ & 3 & $2.9 \%$ & 1 & $1.6 \%$ \\
\hline \begin{tabular}{l} 
Government of Japan \\
\hline I don't know
\end{tabular} & 5 & $6.2 \%$ & 7 & $5.9 \%$ & 8 & $7.8 \%$ & 4 & $6.3 \%$ \\
\hline
\end{tabular}

${ }^{\mathrm{a}}$ Census Regions and Divisions of the United States 


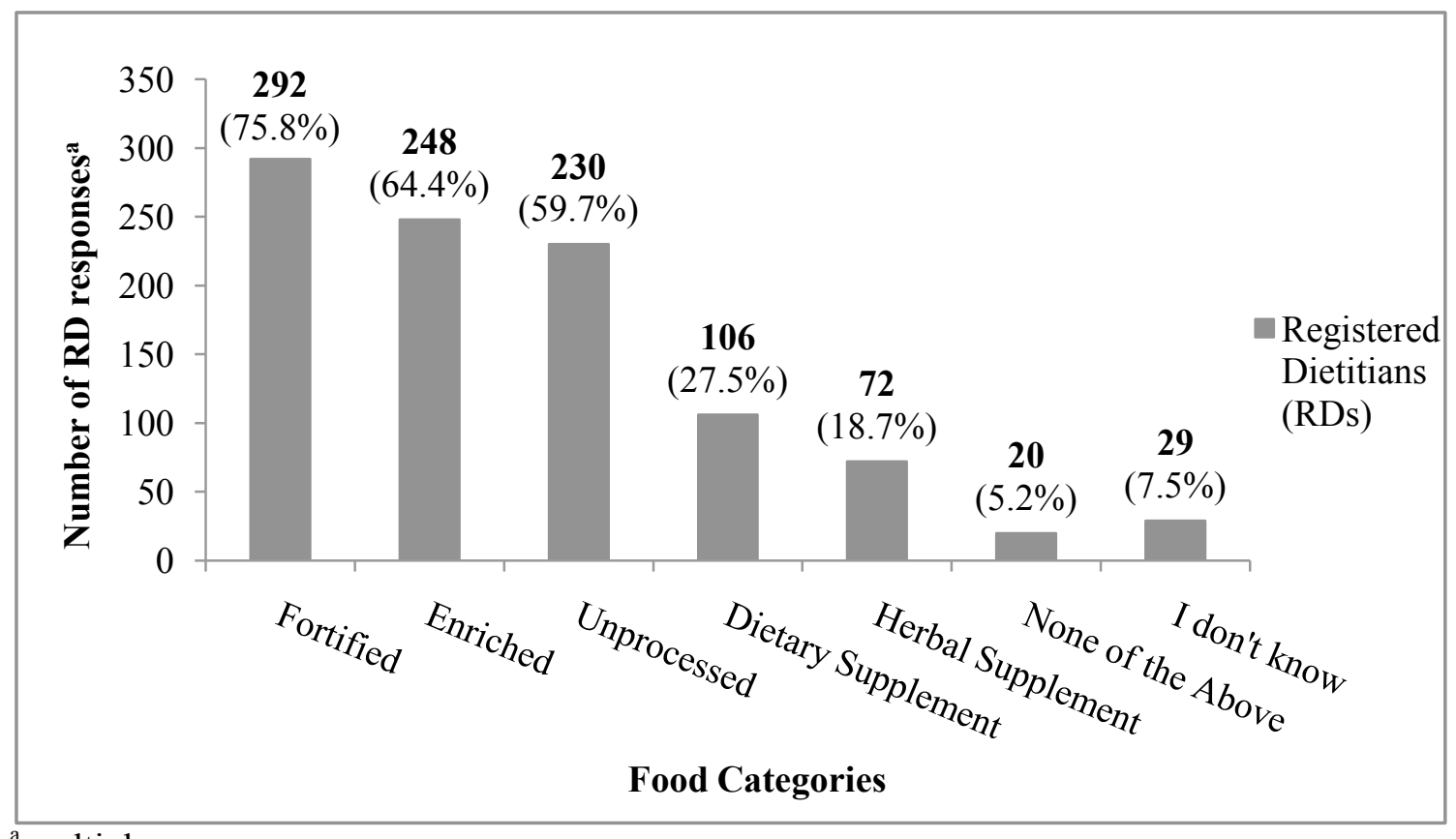

${ }^{\mathrm{a}}$ multiple responses

Figure 1. Food categories Registered Dietitians considered functional foods 
Table 5. Foods Registered Dietitians selected as functional foods MyPyramid food groups ${ }^{\text {a }}$

\begin{tabular}{|c|c|c|c|}
\hline Food Group & Food & $\mathrm{n}$ & $\%$ \\
\hline \multirow[t]{8}{*}{ Grains } & Old Fashioned Oatmeal & 258 & $67.0 \%$ \\
\hline & Chocolate Chip Cookie with Fiber & 218 & $56.6 \%$ \\
\hline & Multi-Grain Bread & 207 & $53.8 \%$ \\
\hline & Instant Oatmeal & 126 & $32.7 \%$ \\
\hline & Cream of Wheat & 88 & $22.9 \%$ \\
\hline & Low-Calorie Bread & 38 & $9.9 \%$ \\
\hline & Low-Fat Chocolate Chip Cookie & 28 & $7.3 \%$ \\
\hline & Chocolate Chip Cookie & 21 & $5.7 \%$ \\
\hline \multirow[t]{9}{*}{ Meat and Beans } & Eggs with Omega 3 Fatty Acids & 328 & $85.2 \%$ \\
\hline & Salmon & 239 & $62.1 \%$ \\
\hline & Black Beans & 207 & $53.8 \%$ \\
\hline & Lentils & 194 & $50.4 \%$ \\
\hline & Tuna & 175 & $45.5 \%$ \\
\hline & Tilapia & 107 & $27.8 \%$ \\
\hline & Eggs & 104 & $27.0 \%$ \\
\hline & Chicken & 75 & $19.5 \%$ \\
\hline & Ground Beef & 64 & $16.6 \%$ \\
\hline \multirow[t]{8}{*}{ Fruits } & Orange Juice with Calcium & 286 & $74.3 \%$ \\
\hline & Blueberries & 256 & $66.5 \%$ \\
\hline & Orange Juice with Glucosamine & 249 & $64.7 \%$ \\
\hline & Cranberry Juice with Pomegranate & 225 & $58.4 \%$ \\
\hline & Whole Tomato & 215 & $55.8 \%$ \\
\hline & Cranberry Juice & 193 & $50.1 \%$ \\
\hline & Orange Juice & 148 & $38.4 \%$ \\
\hline & Ketchup & 78 & $20.3 \%$ \\
\hline \multirow[t]{6}{*}{ Vegetables } & Soybeans & 226 & $58.7 \%$ \\
\hline & Garlic & 220 & $57.1 \%$ \\
\hline & Soybean Products & 212 & $55.1 \%$ \\
\hline & Avocado & 194 & $50.4 \%$ \\
\hline & Carrots & 180 & $46.8 \%$ \\
\hline & Guacamole & 119 & $30.9 \%$ \\
\hline \multirow[t]{4}{*}{ Oils and Fats } & Olive Oil with Omega 3 Fatty Acids & 315 & $81.8 \%$ \\
\hline & Margarine with Plant Stanols and Sterols & 294 & $76.4 \%$ \\
\hline & Olive Oil & 184 & $47.8 \%$ \\
\hline & Margarine & 29 & $7.5 \%$ \\
\hline \multirow[t]{2}{*}{ Milk } & Yogurt with Probiotics & 338 & $87.8 \%$ \\
\hline & Yogurt & 166 & $43.1 \%$ \\
\hline
\end{tabular}

${ }^{a}$ multiple responses 
Table 6. Vitamins, minerals and dietary supplements Registered Dietitians considered functional foods ${ }^{\mathrm{a}}$

\begin{tabular}{llrr}
\hline Food Category & Food & $\mathrm{n}$ & $\%$ \\
\hline Supplements & Flaxseed Oil & 200 & $51.9 \%$ \\
& Fish Oil & 197 & $51.2 \%$ \\
& Dietary Fiber & 189 & $49.1 \%$ \\
& Prebiotics & 187 & $48.6 \%$ \\
& Ginger & 94 & $24.4 \%$ \\
& Ginger Root & 92 & $23.9 \%$ \\
& Glucosamine & 84 & $21.8 \%$ \\
& Ginkgo Biloba & 55 & $14.3 \%$ \\
& Echinacea & 52 & $13.5 \%$ \\
& St. John's Wort & 48 & $12.5 \%$ \\
\hline Vitamins and & Calcium and Vitamin D & 131 & $34.0 \%$ \\
& Folate & 117 & $30.4 \%$ \\
& Vitamin C & 109 & $28.3 \%$ \\
& Vitamin E & 106 & $27.5 \%$ \\
& Multivitamin & 95 & $24.7 \%$ \\
\hline
\end{tabular}

${ }^{\mathrm{a}}$ multiple responses

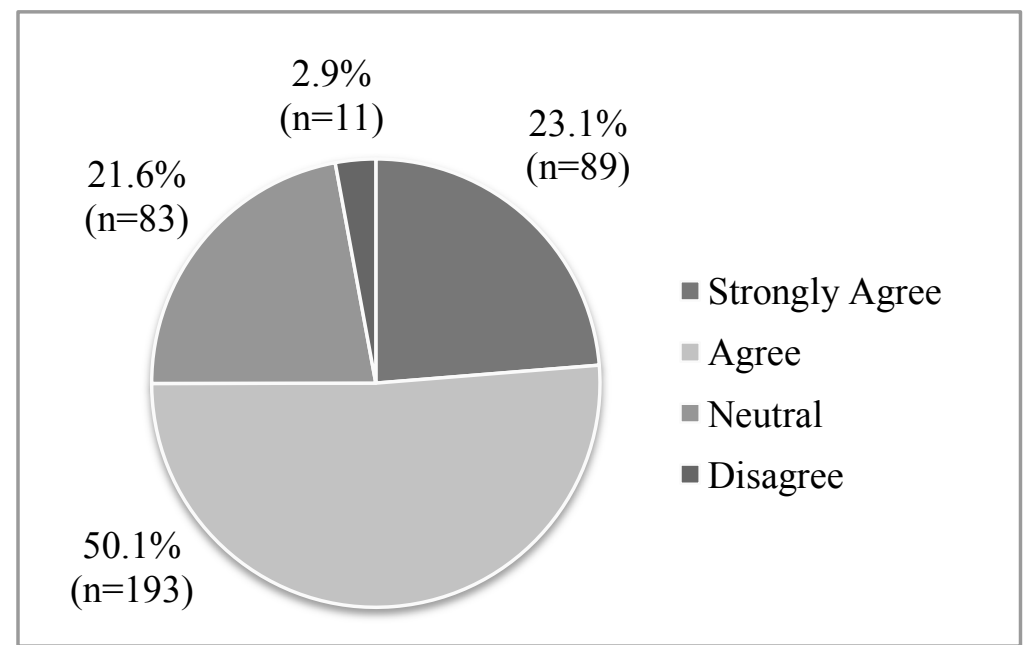

Figure 2. Responses of Registered Dietitians to the statement, "Functional Foods Are Effective In Preventing Disease and Promoting Health" ( $\mathrm{n}=376)$ 


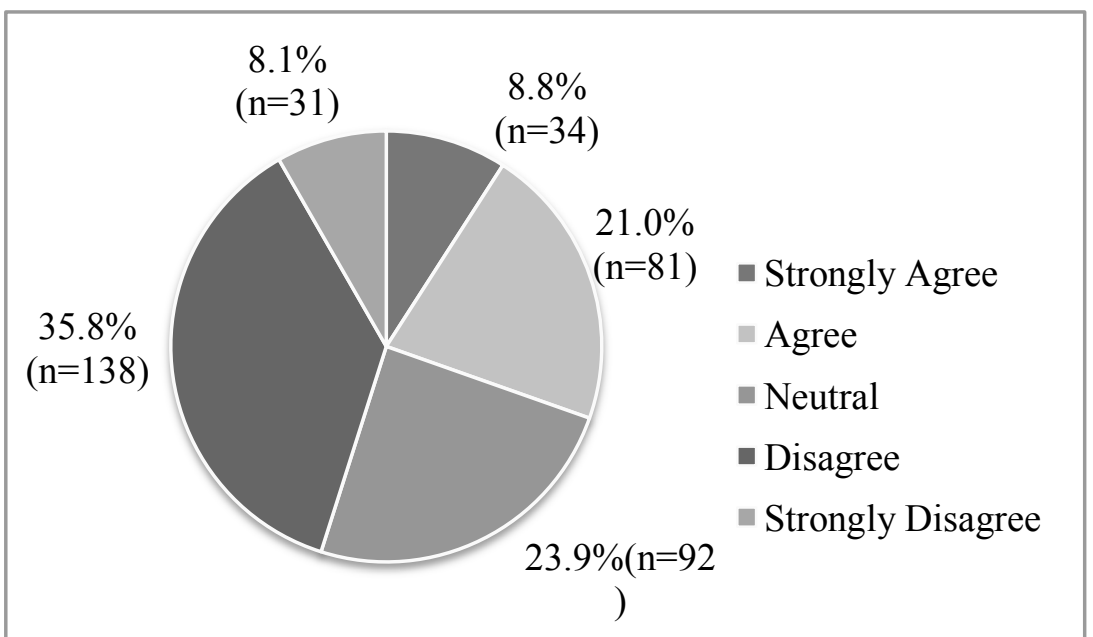

Figure 3. Responses of Registered Dietitians to the statement, "All Foods are Functional" $(\mathrm{n}=376)$

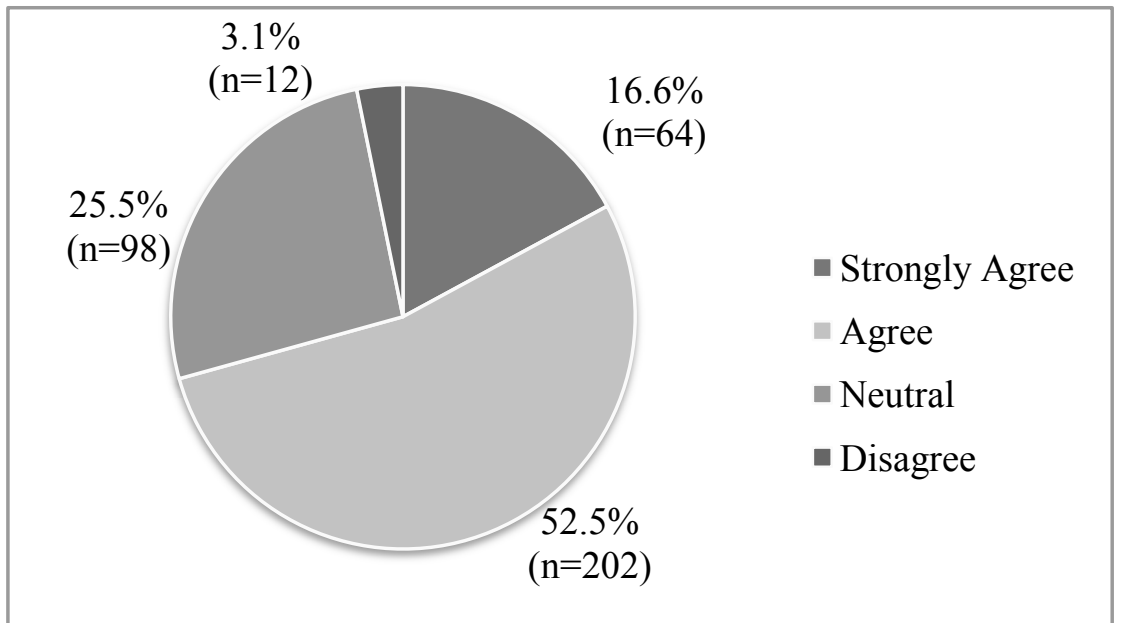

Figure 4. Responses of Registered Dietitians to the statement, "Functional Foods Improve Health" (n=376) 


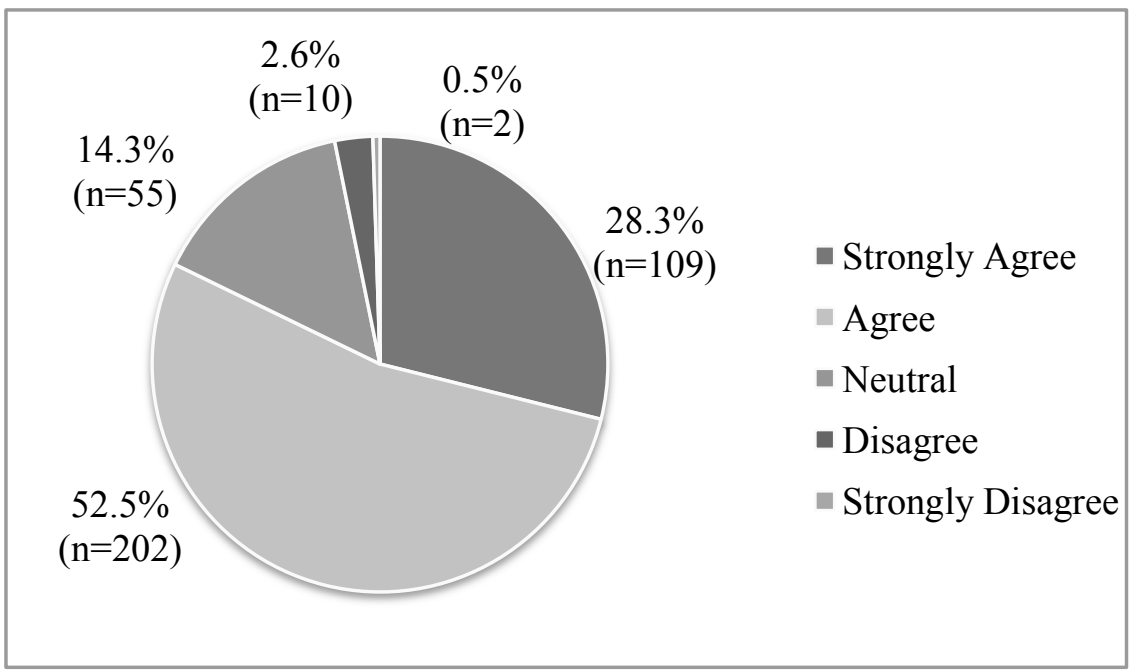

Figure 5. Responses of Registered Dietitians to the statement, "Functional Foods Provide Benefit Beyond Basic Nutrients" ( $n=378$ )

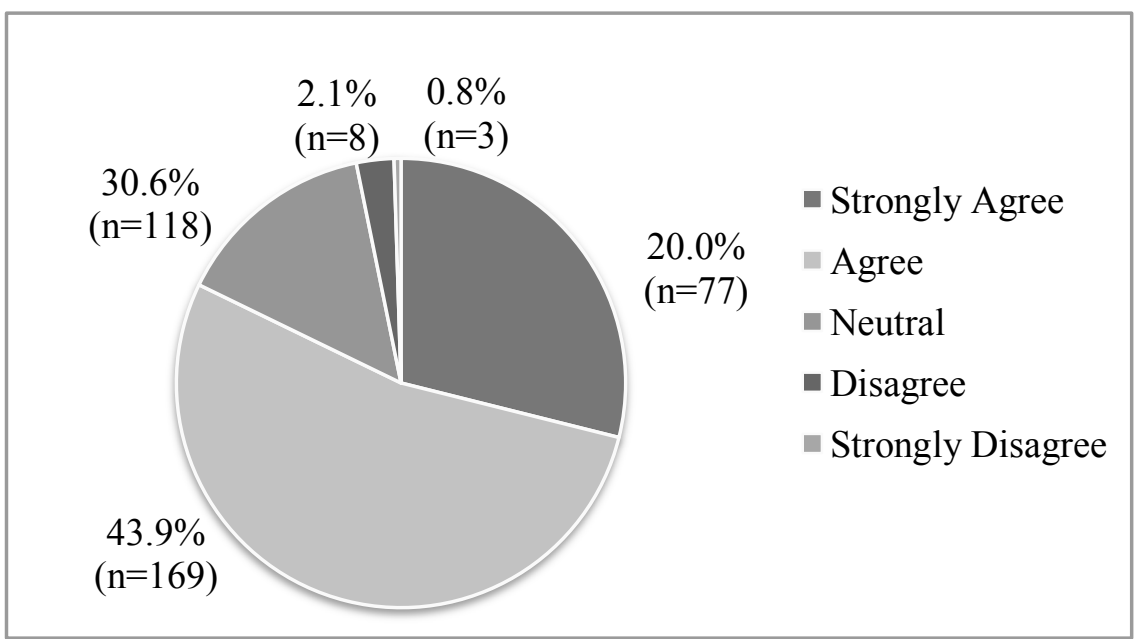

Figure 6. Responses of Registered Dietitians to the statement, "Functional Foods Should be Included as Part of a Treatment Plan for my Clients/Patients" ( $\mathrm{n}=375)$ 


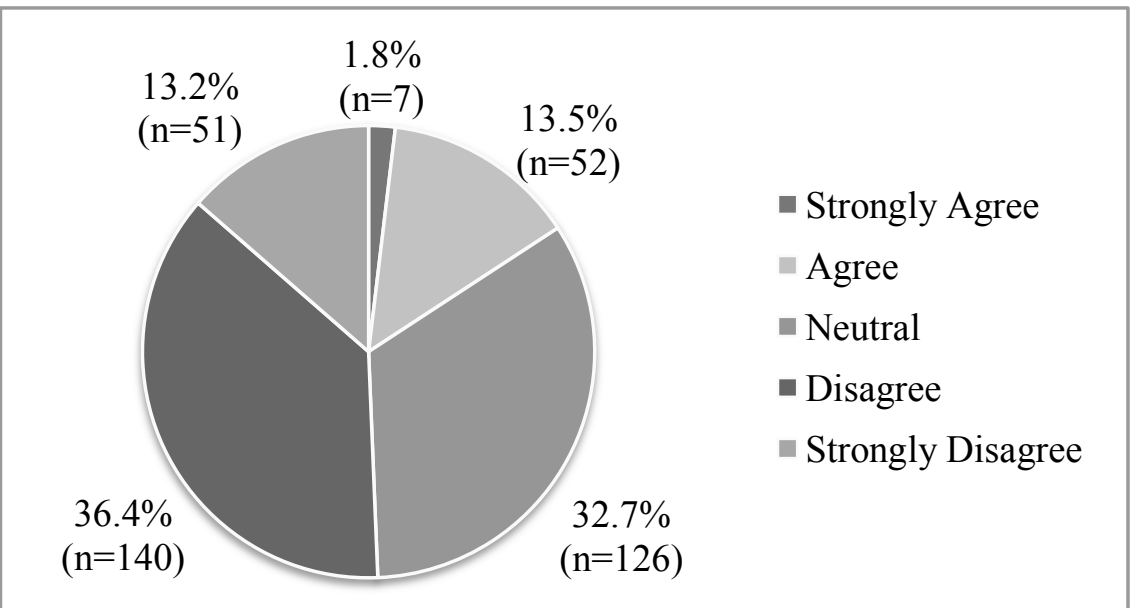

Figure 7. Responses of Registered Dietitians to the statement, "Functional Foods Are Equal To Medication" (n=376)

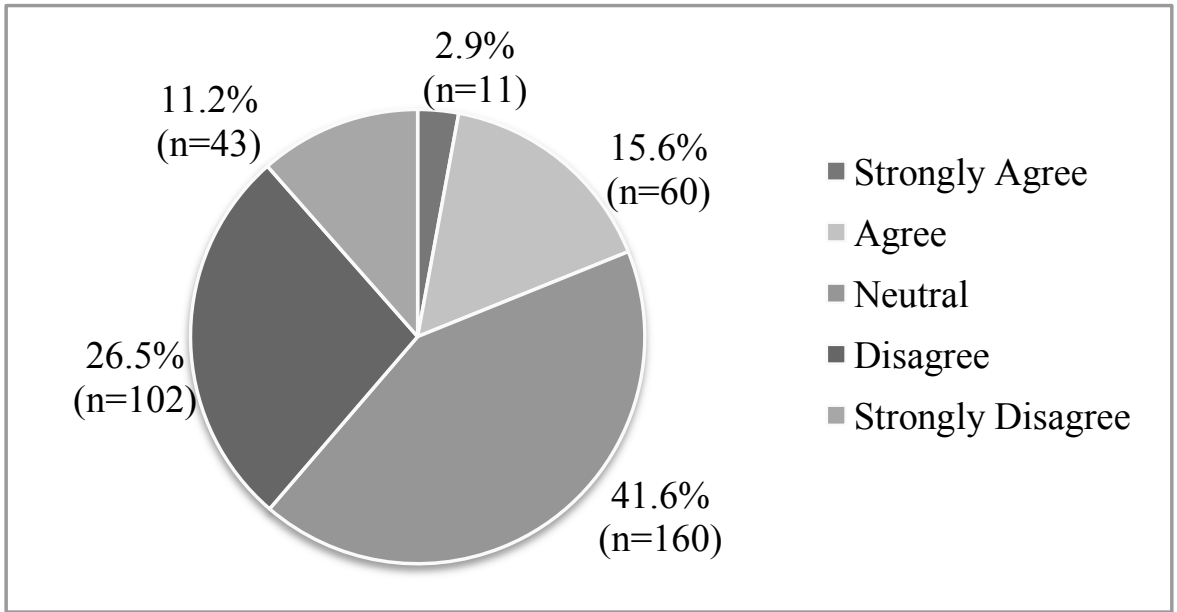

Figure 8. Responses of Registered Dietitians to the statement, "Herbs Should Be Used As Functional Foods"(n=376) 
Table 7. Agreement of Registered Dietitians with functional food statements based on their education $^{\text {a }}$

\begin{tabular}{lcccccc}
\hline Statement & \multicolumn{2}{c}{ Bachelors } & \multicolumn{2}{c}{ Masters } & \multicolumn{2}{c}{ Doctoral } \\
& $\mathrm{n}$ & $\mathrm{n} \%$ & $\mathrm{n}$ & $\%$ & $\mathrm{n}$ & $\%$ \\
\hline & & & & & & \\
\hline $\begin{array}{l}\text { 1) Functional foods are effective in } \\
\text { preventing disease and promoting health. }\end{array}$ & 113 & $73.4 \%$ & 151 & $76.3 \%$ & 17 & $73.9 \%$ \\
\hline $\begin{array}{l}\text { 2) All foods are functional. } \\
\text { 3) Functional foods improve health. }\end{array}$ & 106 & $68.8 \%$ & 144 & $72.8 \%$ & 15 & $65.2 \%$ \\
\hline $\begin{array}{l}\text { 4) Functional foods provide benefit } \\
\text { beyond basic nutrients. }\end{array}$ & 122 & $79.2 \%$ & 168 & $84.0 \%$ & 20 & $87.0 \%$ \\
\hline $\begin{array}{l}\text { 5) Functional foods should be included } \\
\text { as part of a treatment plan for my } \\
\text { patients/clients. }\end{array}$ & 107 & $69.5 \%$ & 131 & $66.1 \%$ & 8 & $36.4 \%$ \\
\hline $\begin{array}{l}\text { 6) Functional foods are equal to } \\
\text { medication. }\end{array}$ & 26 & $16.9 \%$ & 30 & $15.1 \%$ & 3 & $13.0 \%$ \\
\hline $\begin{array}{l}\text { 7) Herbs should be used as functional } \\
\text { foods. }\end{array}$ & 24 & $15.5 \%$ & 43 & $21.7 \%$ & 4 & $17.4 \%$ \\
\hline
\end{tabular}

${ }^{a}$ Strongly agreed and agreed data were aggregated and considered agreement

$* * \mathrm{p}<.001$

Table 8. Agreement of Registered Dietitians with functional food statements according to their region of practice ${ }^{\mathrm{a}}$

\begin{tabular}{|c|c|c|c|c|c|c|c|c|}
\hline \multirow[t]{2}{*}{ Statement } & \multicolumn{2}{|c|}{ Northeast } & \multicolumn{2}{|c|}{ Midwest } & \multicolumn{2}{|c|}{ South } & \multicolumn{2}{|c|}{ West } \\
\hline & $\mathrm{n}$ & $\%$ & $\mathrm{n}$ & $\%$ & $\mathrm{n}$ & $\%$ & $\mathrm{n}$ & $\%$ \\
\hline $\begin{array}{l}\text { 1) Functional foods are effective in } \\
\text { preventing disease and promoting } \\
\text { health. }\end{array}$ & 59 & $75.7 \%$ & 90 & $76.9 \%$ & 80 & $79.2 \%$ & 41 & $67.2 \%$ \\
\hline 2) All foods are functional. & 26 & $32.9 \%$ & 38 & $32.5 \%$ & 29 & $29 \%$ & 17 & $27.9 \%$ \\
\hline 3) Functional foods improve health. & 51 & $64.5 \%$ & 87 & $74.4 \%$ & 73 & $72.3 \%$ & 45 & $75.0 \%$ \\
\hline $\begin{array}{l}\text { 4) Functional foods provide benefit } \\
\text { beyond basic nutrients. }\end{array}$ & 66 & $83.6 \%$ & 100 & $85.5 \%$ & 83 & $82.2 \%$ & 45 & $72.6 \%$ \\
\hline $\begin{array}{l}\text { 5) Functional foods should be } \\
\text { included as part of a treatment plan } \\
\text { for my patients/clients. }\end{array}$ & 52 & $65.8 \%$ & 82 & $70.7 \%$ & 62 & $61.4 \%$ & 40 & $66.7 \%$ \\
\hline $\begin{array}{l}\text { 6) Functional foods are equal to } \\
\text { medication. }\end{array}$ & 15 & $19.0 \%$ & 17 & $14.6 \%$ & 18 & $17.8 \%$ & 8 & $13.3 \%$ \\
\hline $\begin{array}{l}\text { 7) Herbs should be used as } \\
\text { functional foods. }\end{array}$ & 16 & $20.5 \%$ & 16 & $13.7 \%$ & 23 & $22.8 \%$ & 13 & $21.4 \%$ \\
\hline
\end{tabular}

${ }^{\mathrm{a}}$ Strongly agreed and agreed data were aggregated and considered agreement

$* * \mathrm{p}<.001$ 
Table 9. Registered Dietitians' personal consumption, and professional recommendation of functional foods

\begin{tabular}{|c|c|c|c|c|c|c|}
\hline \multirow[t]{2}{*}{ Use of functional foods } & \multicolumn{2}{|c|}{ Yes } & \multicolumn{2}{|c|}{ No } & \multicolumn{2}{|c|}{ I don't know } \\
\hline & $\mathrm{n}$ & $\%$ & $\mathrm{n}$ & $\%$ & $\mathrm{n}$ & $\%$ \\
\hline $\begin{array}{l}\text { Do you personally use functional } \\
\text { foods? }\end{array}$ & 290 & $75.9 \%$ & 67 & $17.5 \%$ & 25 & $6.5 \%$ \\
\hline $\begin{array}{l}\text { Have you recommended a } \\
\text { functional food(s) to a client/ } \\
\text { patient in the past year? }\end{array}$ & 231 & $61.4 \%$ & 124 & $33.0 \%$ & 21 & $5.6 \%$ \\
\hline
\end{tabular}

Table 10. Three identified functional foods Registered Dietitians personally consumed or professionally recommended in the past year, based on written response

\begin{tabular}{lrr}
\hline Functional Food & $\mathrm{n}$ & $\%$ \\
\hline Personally Used & & \\
\hline Fruit & 138 & $48.4 \%$ \\
Yogurt Products $^{\text {a }}$ & 123 & $31.9 \%$ \\
Vegetables & 78 & $20.3 \%$ \\
\hline Professionally Recommended $^{\text {Yogurt Products }}{ }^{\text {a }}$ & & \\
\hline Vegetables $_{\text {Fruit }}$ & 77 & $20.0 \%$ \\
& 50 & $12.9 \%$ \\
\hline
\end{tabular}

${ }^{\mathrm{a}}$ Yogurt products included: regular yogurt, yogurt with probiotics and kefir

Table 11. Registered Dietitians' purposes for professionally recommending functional foods to patients and/or clients in the past year $^{\mathrm{a}}$

\begin{tabular}{lrr}
\hline Purposes & $\mathrm{n}$ & $\%$ \\
\hline Maintenance of good health & & \\
Prevention of chronic disease & 175 & $45.5 \%$ \\
Treatment of chronic disease & 151 & $39.2 \%$ \\
Treatment of acute disease & 123 & $31.9 \%$ \\
\hline
\end{tabular}

${ }^{a}$ multiple responses 
Table 12. Registered Dietitians' purposes for professionally recommending functional foods to patients and/or clients in the past year, according to education ${ }^{\mathrm{a}}$

\begin{tabular}{lcccccc}
\hline Purposes & \multicolumn{2}{c}{ Bachelors } & \multicolumn{2}{c}{ Masters } & \multicolumn{2}{c}{ Doctoral } \\
& $\mathrm{n}$ & $\%$ & $\mathrm{n}$ & $\%$ & $\mathrm{n}$ & $\%$ \\
\hline $\begin{array}{l}\text { Maintenance of good } \\
\text { health }\end{array}$ & 71 & $45.2 \%$ & 97 & $47.5 \%$ & 7 & $30.4 \%$ \\
\hline $\begin{array}{l}\text { Prevention of chronic } \\
\text { disease }\end{array}$ & 62 & $39.5 \%$ & 84 & $41.2 \%$ & 5 & $21.7 \%$ \\
\hline $\begin{array}{l}\text { Treatment of chronic } \\
\text { disease }\end{array}$ & 49 & $31.2 \%$ & 72 & $35.3 \%$ & 2 & $8.7 \%{ }^{*}$ \\
$\begin{array}{l}\text { Treatment of acute } \\
\text { disease }\end{array}$ & 26 & $16.6 \%$ & 34 & $16.7 \%$ & 0 & $0 \%$ \\
$\begin{array}{l}\text { a multiple responses } \\
* \mathrm{p}<.05\end{array}$ & & & & & \\
\hline
\end{tabular}

Table 13. Registered Dietitians' purposes for professionally recommending functional foods to patients and/or clients in the past year, according to Census Regions and Divisions of the United States ${ }^{a b}$

\begin{tabular}{lccrrrrrr}
\hline Purposes & \multicolumn{2}{c}{ Northeast } & \multicolumn{2}{c}{ Midwest } & \multicolumn{2}{c}{ South } & \multicolumn{2}{c}{ West } \\
& $\mathrm{n}$ & $\%$ & $\mathrm{n}$ & $\%$ & $\mathrm{n}$ & $\%$ & $\mathrm{n}$ & $\%$ \\
\hline $\begin{array}{l}\text { Maintenance of } \\
\text { good health }\end{array}$ & 38 & $50.0 \%$ & 43 & $49.4 \%$ & 50 & $47.2 \%$ & 32 & $44.4 \%$ \\
\hline $\begin{array}{l}\text { Prevention of } \\
\text { chronic disease }\end{array}$ & 28 & $36.8 \%$ & 35 & $40.2 \%$ & 44 & $41.5 \%$ & 28 & $38.9 \%$ \\
\hline $\begin{array}{l}\text { Treatment of } \\
\text { chronic disease }\end{array}$ & 28 & $36.8 \%$ & 36 & $41.4 \%$ & 36 & $34.0 \%$ & 16 & $22.2 \%$ \\
\hline $\begin{array}{l}\text { Treatment of } \\
\text { acute disease }\end{array}$ & 7 & $9.2 \%$ & 16 & $18.4 \%$ & 23 & $21.7 \%$ & 12 & $16.7 \%$ \\
\hline
\end{tabular}

a multiple responses

${ }^{\mathrm{b}}$ Census Regions and Divisions of the United States 
Table 14. Source where Registered Dietitians' learned about functional foods ${ }^{\text {a }}$

\begin{tabular}{lcc}
\hline Source & $\mathrm{n}$ & $\%$ \\
\hline & & \\
\hline Professional Conference & 115 & $29.9 \%$ \\
\hline Peer Reviewed Journal & 108 & $28.1 \%$ \\
\hline No Training & 104 & $27.0 \%$ \\
\hline University & 79 & $20.5 \%$ \\
\hline Internet Website & 78 & $20.3 \%$ \\
\hline Other & 63 & $16.4 \%$ \\
\hline
\end{tabular}

${ }^{a}$ multiple responses

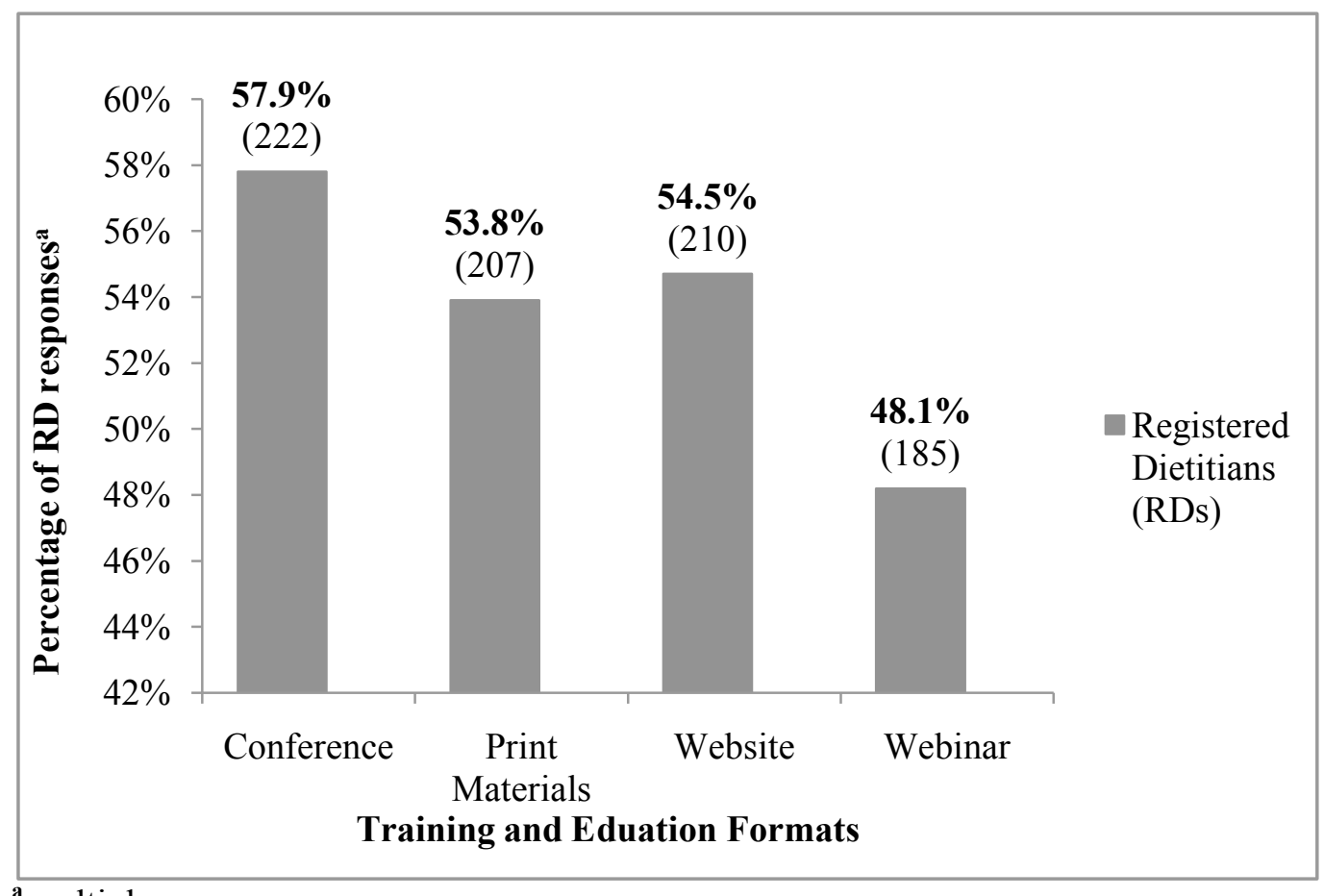

${ }^{a}$ multiple responses

Figure 9. Training and education formats chosen by Registered Dietitians to learn about functional foods, based on multiple responses 


\section{LIST OF REFERENCES}

1. Ares G, Gambaro A. Influence of gender, age and motives underlying food choice on perceived healthiness and willingness to try functional foods. Appetite. 2007;49:148-158.

2. Roberfroid MB. Concepts and strategy of functional food science: the European perspective. Am J Clin Nutr 2000;71(supply):1660S-4S.

3. Arai S, Osawa T, Ohigashi H et al. A Mainstay of Functional Food Science in Japan - History, Present Status, and Future Outlook. Biosci Biotechnol Biochem. 2001;65(1):1-13.

4. Milner JA. Functional foods: the U.S. perspective. Am J Clin Nutr. 2000;71(suppl):1654S-1659S.

5. Position of the American Dietetic Association: Functional Foods. J Am Diet Assoc. 2009;109(4):735-745.

6. Scrinis G. Invited Commentary: Functional foods or functionally marketed foods? A critique of, and alternatives to, the category of 'functional foods.' Public Health Nutr. 2008;11(5):541-545.

7. Tapsell L. Functional foods: An Australian perspective. Nutr Diet. 2008;65(s3):S23-S26.

8. Hasler CM. Functional Foods: Benefits, Concerns and Challenges - A Position Paper from the American Council on Science and Health. J Nutr. 2002;132:37723781 .

9. Ross S. Functional Foods: the Food and Drug Administration perspective. Am J Clin Nutr. 2000;71(suppl):1735S-1738S.

10. International Life Sciences Institute. Safety assessment and potential health benefits of food components based on selected scientific criteria. ILSI North America Technical Committee on Food Components for Health Promotion. Crit Rev Food Sci Nutr. 1999;39(3):203-316.

11. United States Food and Drug Administration. Labeling \& Nutrition: Food Labeling and Nutrition Overview. http:/www.fda.gov/Food/LabelingNutrition/ default.htm. Accessed November 7, 2009.

12. Ares G, Gimenez A, Gambaro A. Influence of nutritional knowledge on perceived healthiness and willingness to try functional foods. Appetite. 2008;51:663-668. 
13. Arai S, Morinaga Y, Yoshikawa T, Ichishi E, Kiso Y, Yamazaki Met al. Recent trends in functional food science and the industry in Japan. Biosci Biotechnol Biochem. 2002;66(10):2017-2029.

14. Palou A, Serra F, Pico C. General aspects on the assessment of functional foods in the European Union. Eur J Clin Nutr 2003;57(supp11):S12-17.

15. Arai S. Mini-review: Functional Food Science in Japan: State of the art. Biofactors. 2000;12:13-16.

16. Lee YK, Georgiou C, Raab C. The knowledge, attitudes, and practices of dietitians licensed in Oregon regarding functional foods, nutrient supplements, and herbs as complementary medicine. J Am Diet Assoc. 2000;100:543-548.

17. Couch LM, Harris JE. Knowledge, Attitudes, and Self-Reported Practices of Pennsylvania Registered Dietitians Regarding Functional Foods and Herbal Medicine. Top Clin Nutr. 2008; 23(1):32-46.

18. Position of The American Dietetic Association: Phytochemicals and functional foods. J Am Diet Assoc. 1995;35(4):493-496.

19. Sheeshka J, Lacroix BJ. Canadian Dietitians' Attitudes Toward Functional Foods and Nutraceuticals. Can J Diet Prac Res. 2008;69:119-125.

20. De Jong N, Hoendervangers CT, Bleeker JK, Ocke MC. The opinion of Dutch dietitians about functional foods. J Hum Nutr Dietet. 2004;17:55-62.

21. United States Department of Agriculture. Inside the Pyramid. http://www.my pyramid.gov/pyramid/index.html. Accessed March 15, 2009.

22. Faul F, Erdfelder E, Lang AG, Buchner A. (2007). G*Power3: A flexible statistical power analysis program for the social, behavioral, and biomedical sciences. Behavior Research Methods. 2007;(39)175-191.

23. United States Census Bureau. Census Regions and Divisions of the United States. http://www.census.gov/geo/www/us_regdiv.pdf. Accessed November 20, 2009.

24. Fowler FJ Jr. Improving survey questions: design and evaluation. Applied Social Research Methods Series. Thousand Oaks, CA: Sage Publications; 1995.

25. Position of the American Dietetic Association: Nutrient Supplementation. $J$ Am Diet Assoc. 2009;109:2073-2085.

26. Position of ADA: Food Fortification and Nutrient Supplementation. J Am Diet Assoc. 2001;101:115-125. 
27. Position of the American Dietetic Association: Health Implications of Dietary Fiber. J Am Diet Assoc. 2008;108:1716-1731.

28. Kris-Etherton P, Fleming J, Harris WS. The Debate About n-6 Polyunsaturated Fatty Acid Recommendations for Cardiovascular Health. $J$ Am Diet Assoc. 2010;110(2):201-204.

29. Harris WS, Millerb M, Tighec AP, Davidsond MH, Schaefere EJ. Omega-3 fatty acids and coronary heart disease risk: Clinical and mechanistic perspectives. Atheros. 2008;197(1):12-24.

30. United States Department of Agriculture. Food Safety and Inspection Recalls. http://www.fsis.usda.gov/FSIS_Recalls/Open_Federal_Cases/index.asp. Accessed on February 18, 2010.

31. Basu A, Imrhan V. Review: Tomato versus lycopene in oxidative stress and carcinogenesis: conclusions from clinical trials. Euro J of Clin Nutr. 2006: 1-9.

32. Giovannucci E. Promises and Perils of Lycopene/Tomato Supplementation and Cancer Prevention: Tomato Products, Lycopene, and Prostate Cancer: A Review of the Epidemiological Literature. J of Clin Nutr. 2005;135:2030S-2031S.

33. Somekawa Y, Chiguchi M, Ishibashi T, Aso T. Soy Intake Related to Menopausal Symptoms, Serum Lipids, and Bone Mineral Density in Postmenopausal Japanese Women. Obst and Gynec. 2001;97(1):109-115.

34. Cheng G, Wilczek B, Warner M, Gustafsson J, Landgren BM. Isoflavone treatment for acute menopausal symptoms. Menopause. 2007;14(3):468-473.

35. Patch CS, Tapsell LC, Williams PG. Plant sterol/stanol prescription is an effective treatment strategy for managing hypercholesterolemia in outpatient clinical practice. J Am Diet Assoc. 2005;105(1):46-52.

36. Katan MB, Grundy SM, Jones P, Law M, Miettinen T, Paoletti R. Efficacy and Saftey of Plant Stanols and Sterols in the Management of Blood Cholesterol Levels. Mayo Clinic Proc. 2003;78:965-978.

37. Kopp-Hoolihan L. Prophylactic and Therapeutic Uses of Probiotics: A review. $J$ Am Diet Assoc. 2001;101(2):229-241.

38. Baroja ML, Kirjavainen PV, Hekmat S, Reid G. Anti-inflammatory effects of probiotic yogurt in inflammatory bowel disease patients. Clin Exp Immunol. 2007;149(3):470-479. 
39. American Dietetic Association: For Health Professionals. http://www.eatright.org/default.aspx. Accessed on February 18, 2010.

40. Siegrist M, Stampfli N, Kastenholz H. Consumers' willingness to buy functional foods. The influence of carrier, benefit and trust. Appetite. 2008;51:526-529.

41. Van Trijp HCM, Van der Lans IA. Consumer perceptions of nutrition and health claims. Appetite. 2007;48(3):305-324. 
APPENDICES 
APPENDIX ONE 


\title{
Survey of the Perceptions, Attitudes and Practices of Registered Dietitians regarding Functional Foods
}

\begin{abstract}
The purpose of this survey is to gain a better understanding of Registered Dietitians' perceptions, attitudes and practices regarding functional foods. The Commission on Accreditation for Dietetics Education provided a sample population and you were chosen to participate based on a set of criteria; Registered Dietitian, not retired and a current resident of the U.S. Please find the letter enclosed outlining the purpose of the study, confidentiality and contact information for results and/or future questions.
\end{abstract}

This questionnaire is double-sided. Please answer all of the questions accurately and honestly. Your participation is greatly appreciated!

Please return the survey in the enclosed envelope by August 3, 2009.

\section{Section 1: Perceptions of Functional Foods}

This section will gather information on Registered Dietitians' perceptions of functional foods. Please consider each question carefully before responding.

1) Choose ONE answer: Please choose the ONE definition that best defines functional foods.

A) Functional foods are "those that by virtue of physiologically active food components provide health benefits beyond basic nutrition."

B) Functional foods are those that have "satisfactorily demonstrated to affect beneficially one or more target functions in the body, beyond adequate nutritional effects in a way that is relevant to either an improved state of health and well-being and/or reduction of risk of disease."

C) Functional foods are "those foods that encompass potentially healthful products including any modified food or ingredient that may provide a health benefit beyond the traditional nutrients it contains."

D) "All foods are functional at some physiological level...functional foods that include whole foods and fortified, enriched or enhanced foods have a potentially beneficial effect on health when consumed as part of a varied diet on a regular basis, at effective levels."

E) Foods that are "composed of functional ingredients that affect the structure and/or function of the body and are used to maintain or regulate specific health conditions."

F) I don't know

2) Choose ALL That Apply: Functional foods include the following:
A) Fortified food products
B) Enriched food products
C) Unprocessed or natural foods
D) Dietary Supplements
E) Herbal Supplements
F) None of the above
G) I don't know 
3) Choose ALL That Apply: Please choose the functional foods from the list below:

YOU MAY CHOOSE MORE THAN ONE ANSWER IN EACH CATEGORY

GRAINS:

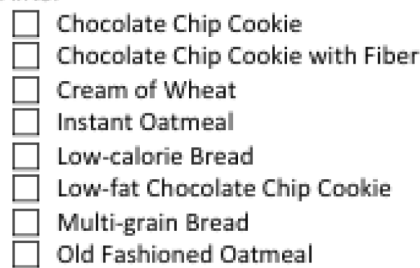

MEAT \& BEANS:

$\square$ Black beans

$\square$ Chicken

$\square$ Eggs

$\square$ Eggs with Omega-3 Fatty Acids

$\square$ Ground Beef

$\square$ Lentils

$\square$ Salmon

$\square$ Tuna

$\square$ Tilapia

SUPPLEMENTS:

$\square$ Dietary Fiber

$\square$ Echinacea

$\square$ Fish Oil

$\square$ Flaxseed Oil

$\square$ Ginger

$\square$ Ginger Root

$\square$ Ginkgo Biloba

$\square$ Glucosamine

$\square$ Prebiotics

$\square$ St. John's Wort

VITAMINS \& MINERALS

$\square$ Calcium and Vitamin D

$\square$ Folate

Multivitamin

$\square$ Vitamin C

Vitamin $\mathrm{E}$

FRUITS:

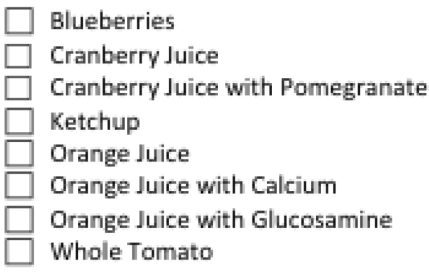

OTHER: 


\section{Section 2: Attitudes about Functional Foods}

This section will gather information pertaining to Registered Dietitian's attitudes with regard to the usage, effectiveness and safety of functional foods. Please consider each question carefully before responding.

\section{『 INDICATE YOUR OPINION OF EACH STATEMENT BY CHECKING THE ONEAPPROPRIATE BOX.}

\begin{tabular}{|c|c|c|c|c|c|}
\hline \multirow{2}{*}{ Statements } & \multicolumn{5}{|c|}{ Please Check ONE per statement } \\
\hline & $\begin{array}{l}\text { Strongly } \\
\text { Agree }\end{array}$ & Agree & Neutral & Disagree & $\begin{array}{l}\text { Strongly } \\
\text { Disagree }\end{array}$ \\
\hline \multicolumn{6}{|l|}{$\begin{array}{l}\text { 4) Functional foods are effective in preventing } \\
\text { disease and promoting health. }\end{array}$} \\
\hline \multicolumn{6}{|l|}{ 5) All foods are functional. } \\
\hline \multicolumn{6}{|l|}{ 6) Functional foods improve health. } \\
\hline \multicolumn{6}{|l|}{$\begin{array}{l}\text { 7) Functional foods provide benefit beyond basic } \\
\text { nutrients. }\end{array}$} \\
\hline \multicolumn{6}{|l|}{$\begin{array}{l}\text { 8) Functional foods should be included as part of } \\
\text { a treatment plan for my patients/clients. }\end{array}$} \\
\hline \multicolumn{6}{|l|}{ 9) Functional foods are equal to medication. } \\
\hline 10) Herbs should be used as functional foods. & & & & & \\
\hline
\end{tabular}




\section{Section 3: Practices of Functional Foods}

This section will gather information pertaining to Registered Dietitian's personal and professional practices with regard to functional foods. Please consider each question carefully before responding.

\section{Personal Use}

11) Choose ONE answer: Do you personally use functional foods?
A) Yes
B) No $\rightarrow$ SKIP TO QUESTION 12
C) I don't know $\rightarrow$ SKIP TO QUESTION 12

a) Please list three (3) functional foods on the lines provided below.

PLEASE GO TO QUESTION 12

\section{Professional Use}

12) Choose ONE answer: Have you recommended a functional food(s) to a client/patient in the past year?

$\square$ A) Yes

B) No $\rightarrow$ SKIP TO QUESTION 13

C) I don't know $\rightarrow$ SKIP TO QUESTION 13

a) Please report which functional foods you recommend:

b) Choose ALL That Apply: Please indicate for what purpose(s) you have recommended functional food(s)?
A) Maintenance of good health
B) Prevention of chronic disease
C) Treatment of chronic disease
D) Treatment of acute disease
E) Other

PLEASE Go TO OUESTION 13 


\section{Section 4: Nutrition Information Source}

This section will gather data pertaining to Registered Dietitians' professional needs, including sources of information and training preferences with regards to functional foods. Please consider each question carefully before responding.

13) Choose ONE answer: Please indicate where you have received your functional food information:

A) University

B) Professional Conference

C) Peer-reviewed journal (please specify)

D) Internet Website (please specify)

E) Other

F) I have not received training on functional foods

14) Choose ONE answer: Would you like to learn about functional foods?

A) Yes

B) No $\rightarrow$ SKIP TO QUESTION 15

Choose ALL That Apply: What is your preferred training or education format for learning about functional foods?

A) Conferences or workshops

B) Books, journals and other written materials

C) Web site

D) Webinar (Internet - Interactive Conference)

E) Other (please specify)

PLEASE GO TO OUESTION 15

\section{Section 5: Demographics}

This section will gather background information of respondents. Please answer all of the questions.

15) Choose ONE answer: What is your age?
$\square$ A) 25 or younger
B) 26-35 years old
$\square$ C) $36-45$ years old
$\square$ D) $46-55$ years old
$\square$ E) $56-65$ years old
$\square$ F) $66+$ years old

16) Choose ONE answer: What is your gender?

$\square$ A) Male

$\square$ B) Female 
17) Choose ONE answer: What is the highest level of education you have completed?
$\square$ A) Bachelor's degree
$\square$ B) Master's degree
$\square$ c) Doctoral degree

18) Choose ONE answer: What is your ethnicity?
$\square$ A) American Indian or Alaskan native
$\square$ B) Asian or Pacific Islander
$\square$ C) Black/African American
$\square$ D) Hispanic/Latino
$\square$ E) White/Caucasian
$\square$ F) Other (Please specify)

19) Choose ONE answer: Was an education component on functional foods included in your dietetics program at the university?

$\square$ A) Yes

$\square$ B) No, functional foods did not exist while I was in school

$\square$ C) No, I was not taught about functional foods in school

$\square$ D) Other (Please specify]

20) Please provide the state where you received your terminal dietetics/nutrition degree:

21) Please provide the state where you completed your internship/practice program:

22) Choose ONE answer: What is your current employment status as a Registered Dietitian?
$\square$ A) Full - time - 40 hrs / week or more
$\square$ B) Part - time - less than 40 hrs / week
$\square$ C) Unemployed
$\square$ D) Not currently working as an RD
$\square$ E) Retired

23) Please provide the state in which you practice

24) Choose ONE answer: Which one of the following describes your work environment?
A) Community-Based Organizations
$\square$ B) Education Institution
$\square$ C) Clinical
$\square$ D) Private Practice
$\square$ E) Government
$\square$ F) Food Industry
$\square$ G) Other (Please specify):

THIS IS THE END OF THE SURVEY ON FUNCTIONAL FOODS. THANK YOU FOR YOUR TIME AND COOPERATION IN COMPLETING THIS SURVEY! 
APPENDIX TWO 


\section{Survey of the Knowledge, Attitudes and Self-Reported Behaviors of Pennsylvania Registered Dietitians regarding Functional Foods and Herbal Medicine as Complementary Medicines}

Dear Colleague:

For the purpose of this study, terms are defined as follows:

Complementary Medicine: an approach to medical diagnosis and treatment that uses alternative therapies as an adjunct to, and not simply a replacement for, conventional medicine. Functional foods and herbal medicine are examples of complementary medicine.

Phytochemicals: nonnutrient compounds found in plant-derived foods that have biological activity in the body.

Functional Foods: a food that contains phytochemicals which provide a physiologic benefit in addition to its nutrient content that may prevent disease and/or promote health. For example, yellow/orange fruits and vegetables contain carotenoid color pigments such as lycopene, lutein and beta-carotene act as antioxidants to protect against certain cancers.

Herb or Herbal: a plant with leaves, roots, stems, or flowers used to treat disease and enhance health. Also known as Botanical medicine. For example, ginseng root may improve glucose control in those with Type II diabetes as well as helping to fight stress-induced fatigue by slowing the release of stress hormones.

\section{Demographics}

The purpose of this survey is to gain a better understanding of Pennsylvania Registered Dietitians' views regarding functional foods and herbal medicine. The survey is confidential. Please answer the following questions as accurately and honestly as possible.

■ PLEASE CHECK THE ONE APPROPRIATE ANSWER BELOW.

1. What is your age?

$\square$ 19-25 vears old

$\square$ 26-35 years old

$\square 36-45$ years old

$\square$ 46-55 vears old

$\square$ 56-65 vears old

$\square 66+$ years old

$\square$ Other (Please specify)

2. Which best describes your ethnic background? (Optional)

$\square$ Aleut, Eskimo, or American Indian

$\square$ Asian or Pacific Islander

$\square$ Black

$\square$ Hispanic

$\square$ White

Other (Please specify):
3. How many years have you been a Registered Dietitian?

1-5 years

$\square$ 6-15 years

$\square 16-25$ years

over 25 years

4. Which is the highest level of education you have completed?

$\square$ Bachelor's degree

$\square$ Master's degree

Doctoral degree

5. What is your gender?

$\square$ Male

Female 
6. What is your current employment status as a Registered Dietitian?

$\square$ Full - time - 40 hrs / week or more

$\square$ Part - time - less than 40 hrs /week

$\square$ Unemployed

$\square$ Retired

$\square$ Not currently working as an RD

7. Which one of the following describes your work environment?

$\square$ Community-based organizations

$\square$ Education institution

$\square$ Healthcare facility

$\square$ Private Practice

$\square$ Government office

$\square$ Other (Please specify):

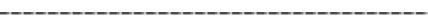

10. How would you describe the majority of your clientele?

$\square$ Primarily older/geriatric (greater than 60 years old)

$\square$ Primarily pediatric/ young adults (birth to 30 years old)

$\square$ Primarily adult ( $31-59$ years old)

$\square$ All ages

$\square$ Other (Please specify)

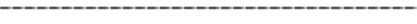

11. What is the most prevalent ethnic group you serve?

$\square$ Aleut, Eskimo, or American Indian

$\square$ Asian or Pacific Islander

$\square$ Black

$\square$ Hispanic

$\square$ White

$\square$ Equal mixture of all backgrounds

$\square$ Other (please specify)
8. What is your religious affiliation or preference? (Optional)

$\square$ Buddhist

$\square$ Catholic

$\square$ Hindu

$\square$ Jewish

$\square$ Muslim

$\square$ Protestant

$\square$ Other

9. What is the type of population you primarily serve?

$\square$ Rural

$\square$ Greater Metropolitan Area

$\square$ Institutionalized Population (prison, rehabilitation, schools, etc.

$\square$ Suburban/ Residential Area

$\square$ Other (please specify)

12. What percent of your clientele inquire about functional foods and/or herbal medicine?

$\square 0-15 \%$

$\square 16-30 \%$

$\square 31-45 \%$

$\square$ 46-60\%

$\square$ 61-75\%

$\square 76-90 \%$

$\square$ Greater than $90 \%$

13. What percent of your clientele use functional foods and for herbal remedies

$\square 0-15 \%$

$\square$ 16-30\%

$\square 31-45 \%$

$\square$ 46-60\%

$\square$ 61-75\%

$\square 76-90 \%$

Greater than $90 \%$ 


\section{Self Reported Practices}

This section will help determine the trends regarding the use of Functional foods and Herbal medicine among Pennsylvania Registered Dietitians.

๑ PLEASE CHECK THE ONE APPROPRIATE ANSWER BELOW.

1. Have you ever personally used herbal supplements or remedies?

No

$\square$ Yes (Please specify)

2. Do you actively include functional foods into your diet in order to maintain or improve health? $\square$ No

$\square$ Yes (Please specify the most common functional food(s) you use)

3. Do you currently use herbal supplements/remedies of any kind?

No

$\square$ Yes (Please specify the most common herb you use)

4. Do you routinely recommend specific functional foods to your clients / patients in order to maintain or improve their health?

$\square$ No

$\square$ Yes (Please specify most common)

5. Do you routinely recommend herbal supplements / remedies to your clients / patients in order to maintain or improve their health?

$\square$ No

$\square$ Yes (Please specify most common)

6. Have you ever, or would you refer a patient / client to an herbal specialist?

$\square$ No

$\square$ Yes

7. Have you had any training to learn more about functional foods?

$\square$ No

$\square$ Yes

8. Have you had any training to learn more about herbal medicine?

$\square$ No

$\square$ Yes 


\section{Attitudes about Safety and Effectiveness}

This section will gather information pertaining to Registered Dietitian's attitudes and beliefs with regard to the usage, effectiveness and safety of functional foods and herbal medicine. Please consider each question carefully before responding.

■ INDICATE YOUR OPINION OF EACH STATEMENT BY CHECKING THE ONE APPROPRIATE BOX.

\begin{tabular}{|c|c|c|c|c|c|}
\hline \multirow[b]{2}{*}{ Statements } & \multicolumn{5}{|c|}{ Please Check One } \\
\hline & $\begin{array}{l}\text { Strongly } \\
\text { Agree }\end{array}$ & Agree & Neutral & Disagree & $\begin{array}{l}\text { Strongly } \\
\text { Disagree }\end{array}$ \\
\hline $\begin{array}{l}\text { 1. The use of herbal medicine has increased } \\
\text { significantly in recent years. }\end{array}$ & & & & & \\
\hline $\begin{array}{l}\text { 2. Changes in the practice and coverage of } \\
\text { medical care have increased patients" } \\
\text { interest in herbal medicine. }\end{array}$ & & & & & \\
\hline $\begin{array}{l}\text { 3. Functional foods can be used to prevent } \\
\text { disease and promote health. }\end{array}$ & & & & & \\
\hline 4. Many herbs have valid medical uses. & & & & & \\
\hline $\begin{array}{l}\text { 5. The use of functional foods improves } \\
\text { health. }\end{array}$ & & & & & \\
\hline $\begin{array}{l}\text { 6. I am interested in learning about current } \\
\text { herbal therapies available on the market. }\end{array}$ & & & & & \\
\hline $\begin{array}{l}\text { 7. I am interested in learning about } \\
\text { functional foods and their effect on } \\
\text { health. }\end{array}$ & & & & & \\
\hline $\begin{array}{l}\text { 8. Herbal supplements should not be } \\
\text { promoted unless they are given FDA } \\
\text { approval. }\end{array}$ & & & & & \\
\hline $\begin{array}{l}\text { 9. Registered Dietitians should be the } \\
\text { primary educators concerning the } \\
\text { possible positive or negative effects of } \\
\text { herbal supplements. }\end{array}$ & & & & & \\
\hline
\end{tabular}




\begin{tabular}{|l|l|l|l|l|l|}
\multicolumn{1}{|c|}{ Statement } & $\begin{array}{c}\text { Strongly } \\
\text { Agree }\end{array}$ & Agree & Neutral & Disagree & $\begin{array}{c}\text { Strongly } \\
\text { Disagree }\end{array}$ \\
\hline $\begin{array}{c}\text { 10. Registered Dietitians should be the } \\
\text { primary educators concerning the } \\
\text { possible positive or negative effects of } \\
\text { functional foods. }\end{array}$ & & & & & \\
\hline $\begin{array}{c}\text { 11. I would discourage an interested client } \\
\text { from trying herbal medicine as an } \\
\text { alternative to traditional medicine. }\end{array}$ & & & & & \\
\hline
\end{tabular}

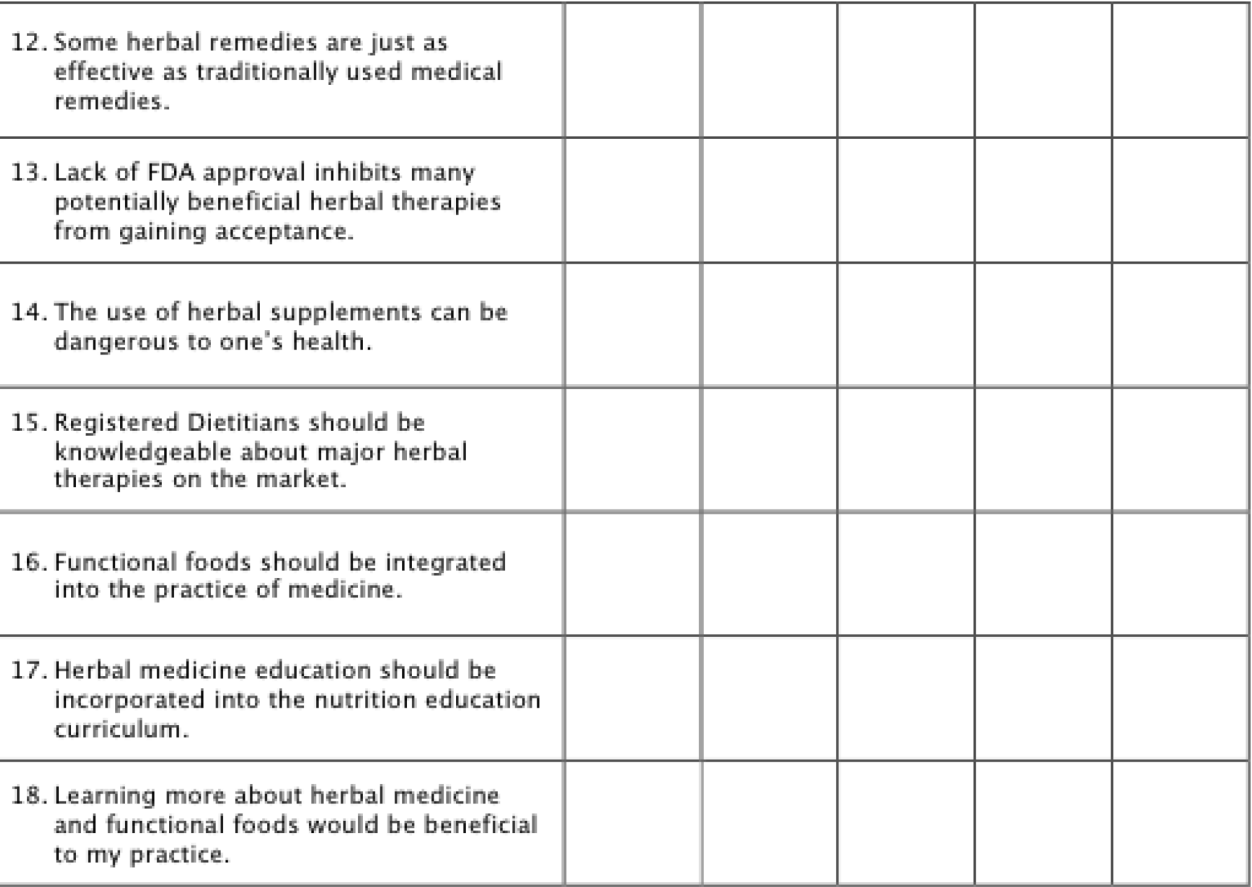

\begin{tabular}{|l|l|l|l|l|}
$\begin{array}{l}\text { 19. I feel qualified to educate my patients / } \\
\text { clients about herbal remedies and } \\
\text { preparations. }\end{array}$ & & & & \\
\hline $\begin{array}{l}\text { 20. I feel qualified to recommend specific } \\
\text { functional foods as part of a treatment } \\
\text { plan to my patients/ clients. }\end{array}$ & & & & \\
\hline
\end{tabular}




\begin{tabular}{|l|l|l|l|l|l|}
\hline \multicolumn{1}{|c|}{ Statement } & $\begin{array}{c}\text { Strongly } \\
\text { Agree }\end{array}$ & Agree & Neutral & Disagree & $\begin{array}{c}\text { Strongly } \\
\text { Disagree }\end{array}$ \\
\hline $\begin{array}{c}\text { 21. Stricter regulations of herbal remedies } \\
\text { are needed. }\end{array}$ & & & & & \\
\hline $\begin{array}{c}\text { 22. I believe that most claims about } \\
\text { functional foods are true. }\end{array}$ & & & & & \\
\hline
\end{tabular}

23. Who should be the primary dispenser of information about herbal medicine?

$\square$ Registered dietitians/ Nutritionist

$\square$ Physicians

$\square$ Pharmacists

$\square$ Herbal specialist

$\square$ other

24. Who should be the primary dispenser of information about functional foods?

$\square$ Registered dietitians/ Nutritionist

$\square$ Physicians

$\square$ Pharmacists

$\square$ Herbal specialist

$\square$ Other

\section{Experience}

This section will gather information on the current experience of Registered Dietitians with regard to Functional foods, and Herbal medicine.

PLEASE INDICATE YOUR RESPONSE BY CHECKING THE ONE APPROPRIATE ANSWER BELOW $\square$.

1. How would you rate your knowledge of current information on herbal remedies?

$\square$ Excellent

$\square$ Good

$\square$ Fair

$\square$ Poor

2. How would you rate your knowledge of current information on functional foods?

$\square$ Excellent

$\square$ Good

$\square$ Fair

$\square$ Poor 
3. Avocados are considered to be functional foods because they have which one of the following health benefits?

$\square$ Improves energy levels.

$\square$ Lowers blood cholesterol.

$\square$ Helps in weight loss.

$\square$ Improves cognitive functioning.

4. The serious adverse reactions of which herb has resulted in its removal from the herbal market?

$\square$ st. John's Wort (Hypericum Perforatum)

$\square$ Blue Cohosh (Caulophyllum Tahlictroides)

$\square$ Ephedra

$\square$ Echinacea

5. Which functional food is commonly used in the treatment of menopausal symptoms for its weak estrogenic - like activity?

$\square$ Broccoli and cauliflower.

$\square$ Soybeans and soy products.

$\square$ Green, red, yellow vegetables and fruits.

$\square$ Garlic and onions.

6. Which herb is commonly used in the treatment of depression?
$\square$ Melanex
$\square$ Feverfew
$\square$ St. John's Wort
$\square$ Gingko Biloba

7. People who eat large amounts of fruits and vegetables are about half as likely to develop cancer.

$\square$ True

$\square$ False

8. Gingko Biloba increases which of the following physiological functions?

$\square$ Metabolism

$\square$ Nutrient absorption

$\square$ Blood flow to the brain

$\square$ Heart rate

9. This organization currently monitors and approves all items labeled as herbal supplements?

$\square$ FDA (Food and Drug Administration)

$\square$ NIH (National Institute of Health)

$\square$ WHO (World Health Organization)

$\square$ There is no regulation of herbal supplements.

10. Which herb is currently used internally to help curb colds and chronic infections of the respiratory tract and lower urinary tract?

$\square$ Purple Cone Flower (Echinacea)

$\square$ Pimento (Pimaenta Racemosa)

$\square$ Black Cohosh (Cimicifuga Racemosa)

$\square$ St. John's Wort (Hypericum Perforatum) 
11. Which phytochemical found in tomatoes has been shown to reduce the risk for prostate cancer?

$\square$ Allyl Sulfides.

$\square$ Lycopene.

$\square$ Isoflavones.

$\square$ Flavonoids.

12. What has been your greatest source of information about complementary medicine?

$\square$ Continuing Education Programs and Seminars

$\square$ Journal Articles

$\square$ Colleagues

$\square$ Patients / Clients

$\square$ Media sources such as TV, radio and newspaper articles

13. Are you aware that a Physician's Desk Reference for herbs is available?

$\square$ No

$\square$ Yes

14. As of 1994, the Dietary Supplement and Health Education Act (DSHEA) requires no proof of efficacy nor safety and sets no standards for quality control for products labeled as supplements.

$\square$ True

$\square$ False

15. Are you confident in recommending functional foods to maintain health and prevent disease?

$\square$ No

$\square$ Yes

$\square$ Not Sure

16. Are you confident in recommending herbal preparations to maintain health and prevent disease?

$\square$ No

$\square$ Yes

$\square$ Not Sure

17. In which area of complementary medicine would you be most interested in receiving additional training or education?

$\square$ Functional foods

$\square$ Herbal Medicine

18. What is your preferred training or education format for complementary medicine?

$\square$ Conferences or workshops

$\square$ Books, journals and other written materials

$\square$ ADA Web site

$\square$ Other Web sites.

19. What is your dietetic specialty?

THIS IS THE END OF THE SURVEY ON COMPLEMENTARY MEDICINE. THANK YOU FOR YOUR COOPERATION AND TIME IN COMPLETING THIS SURVEY! 
APPENDIX THREE 

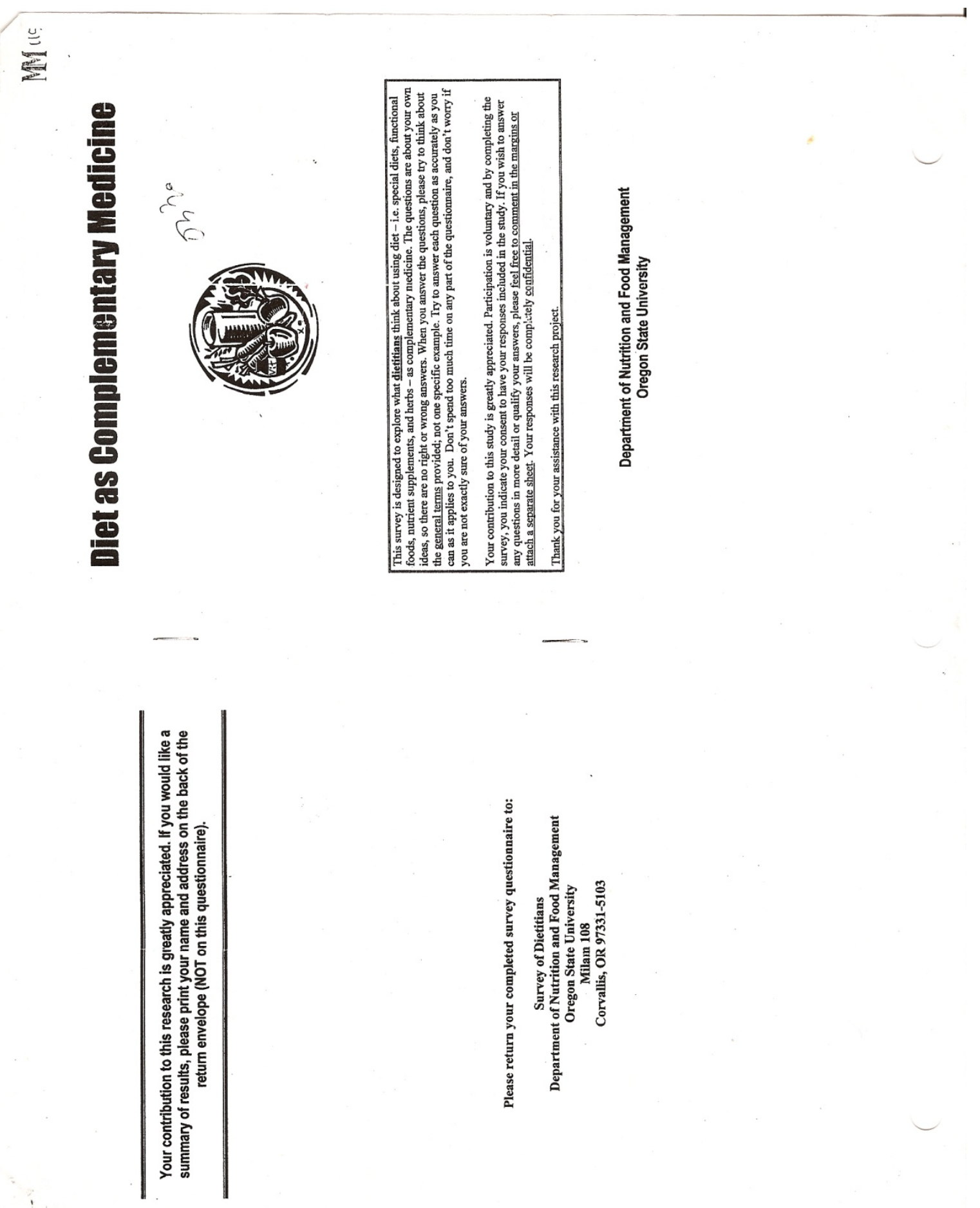

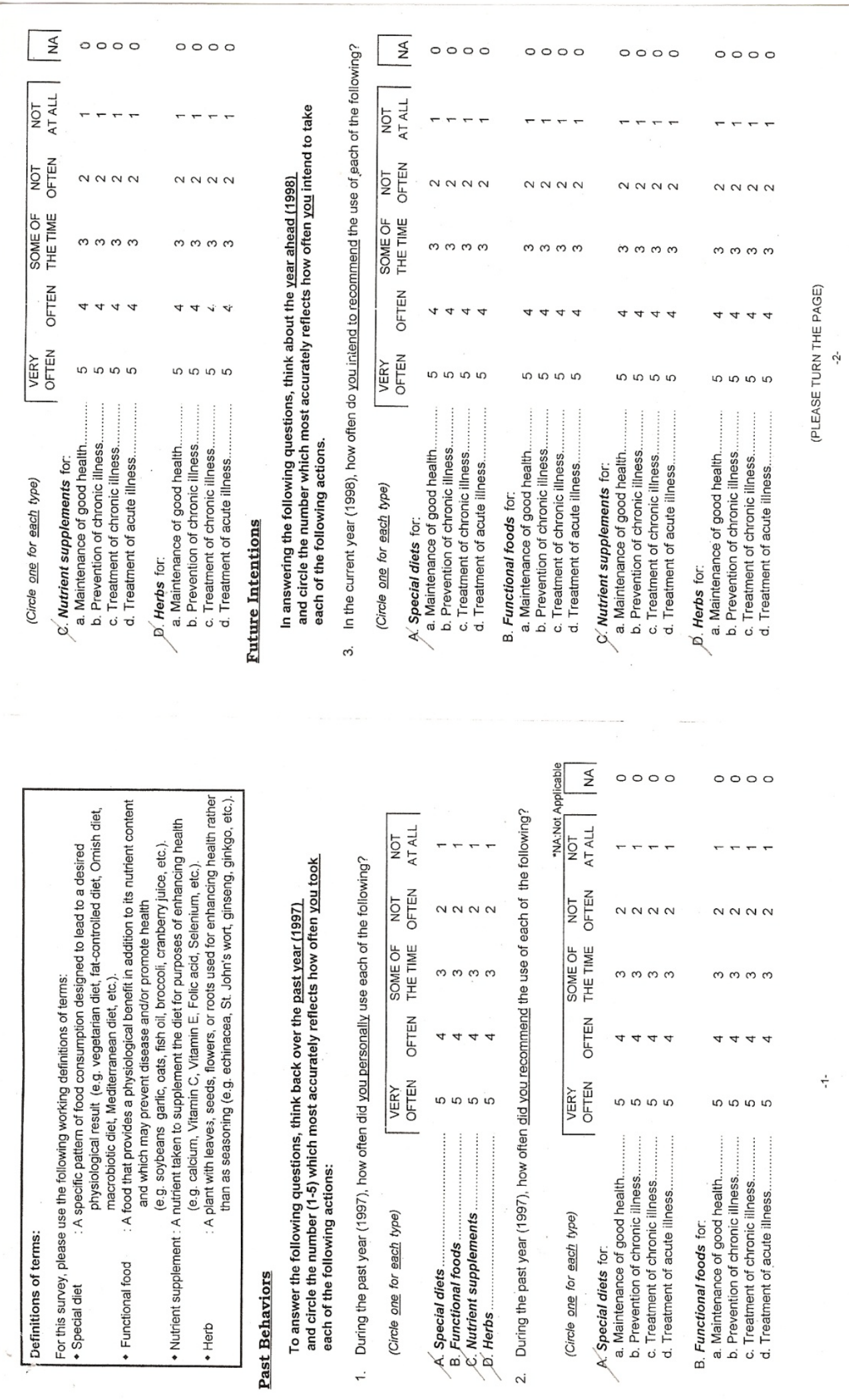

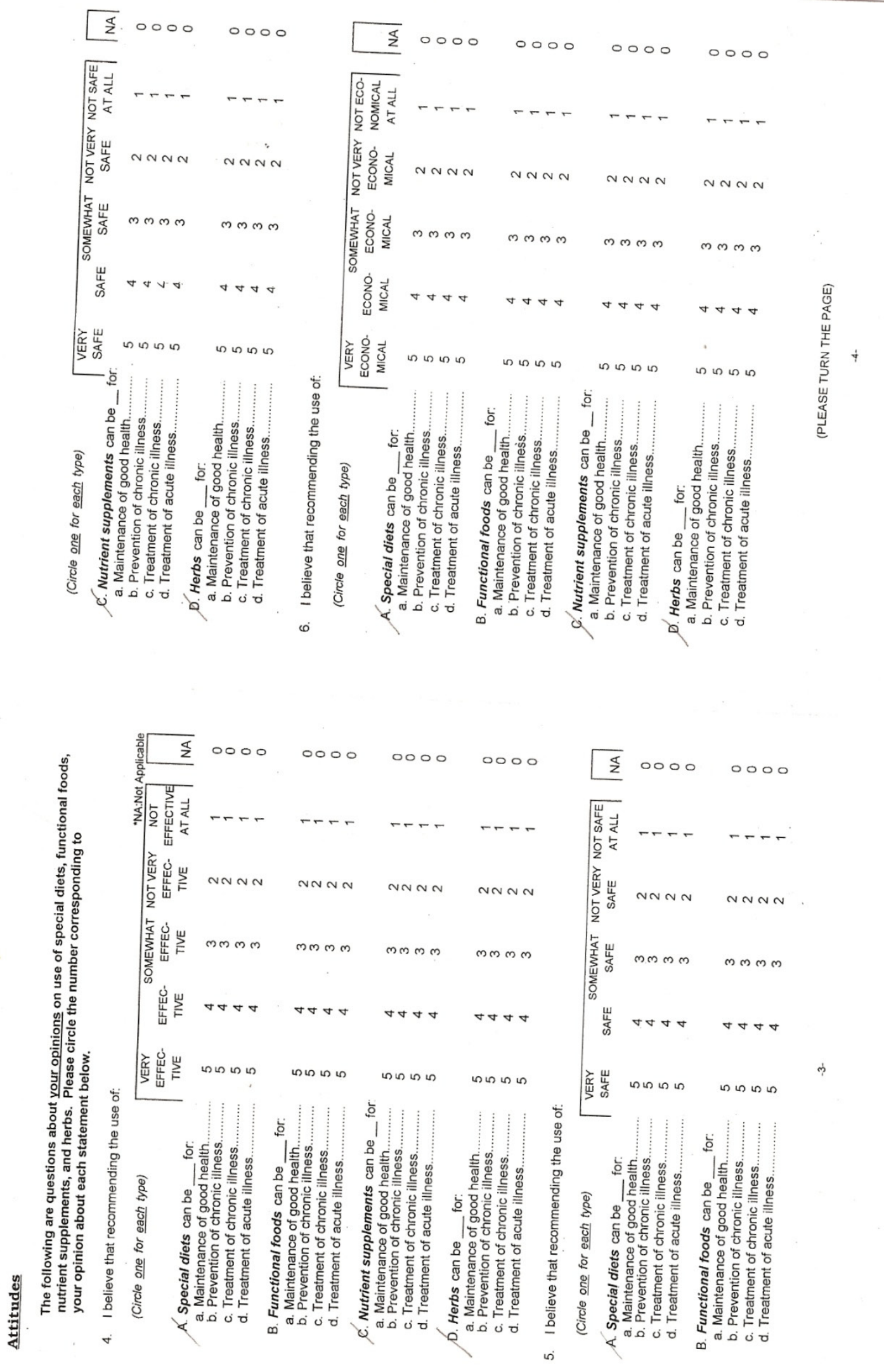

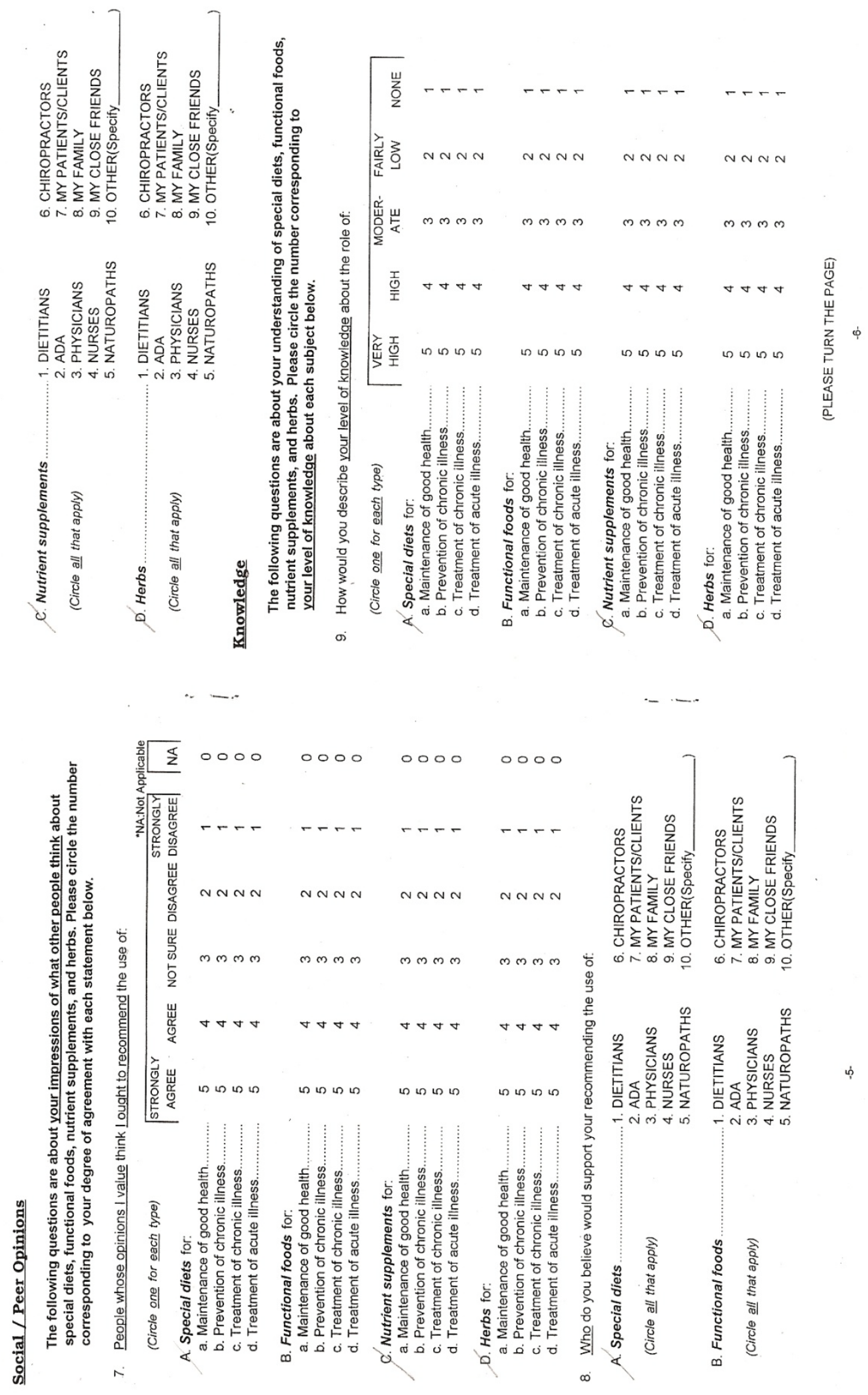

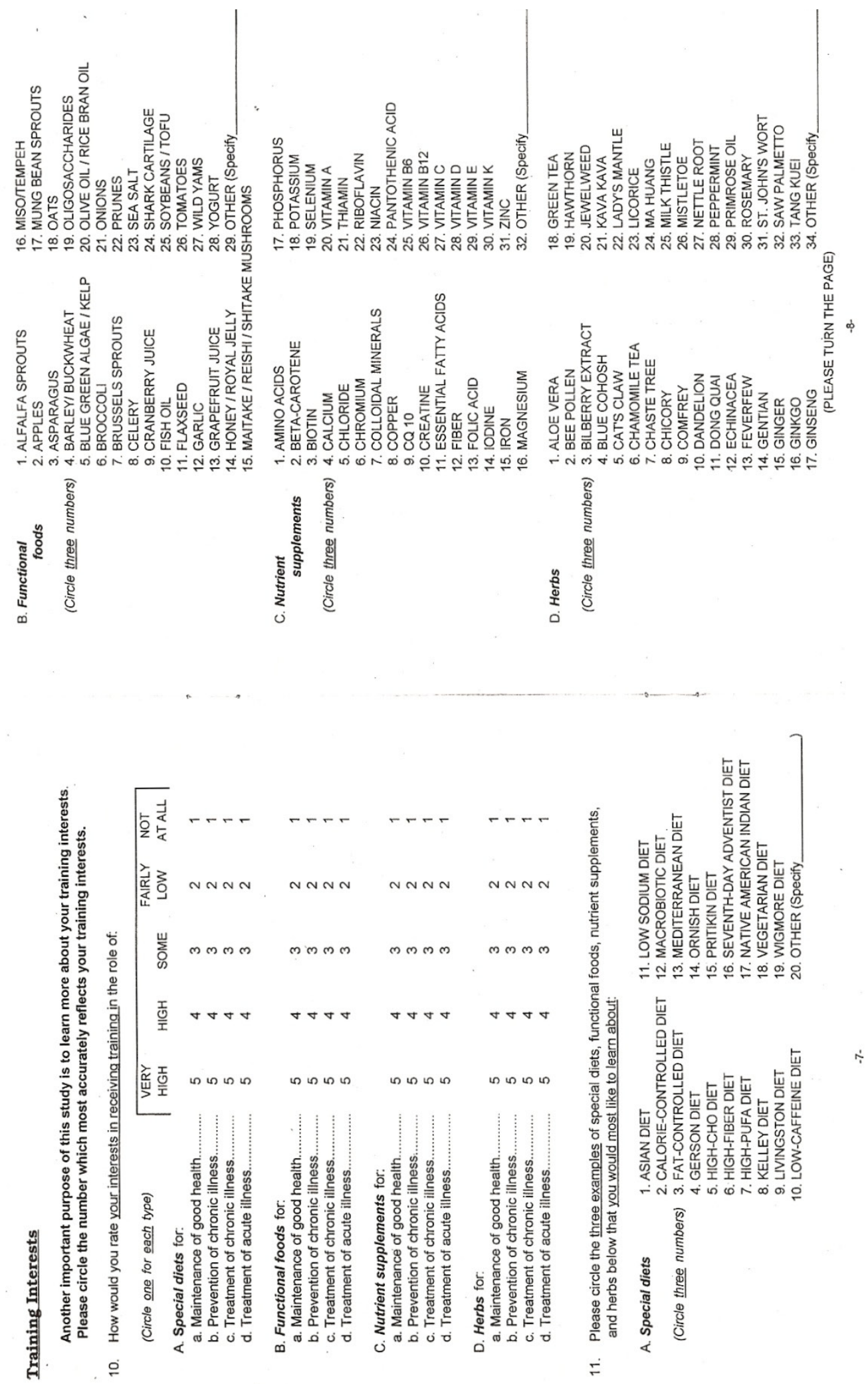

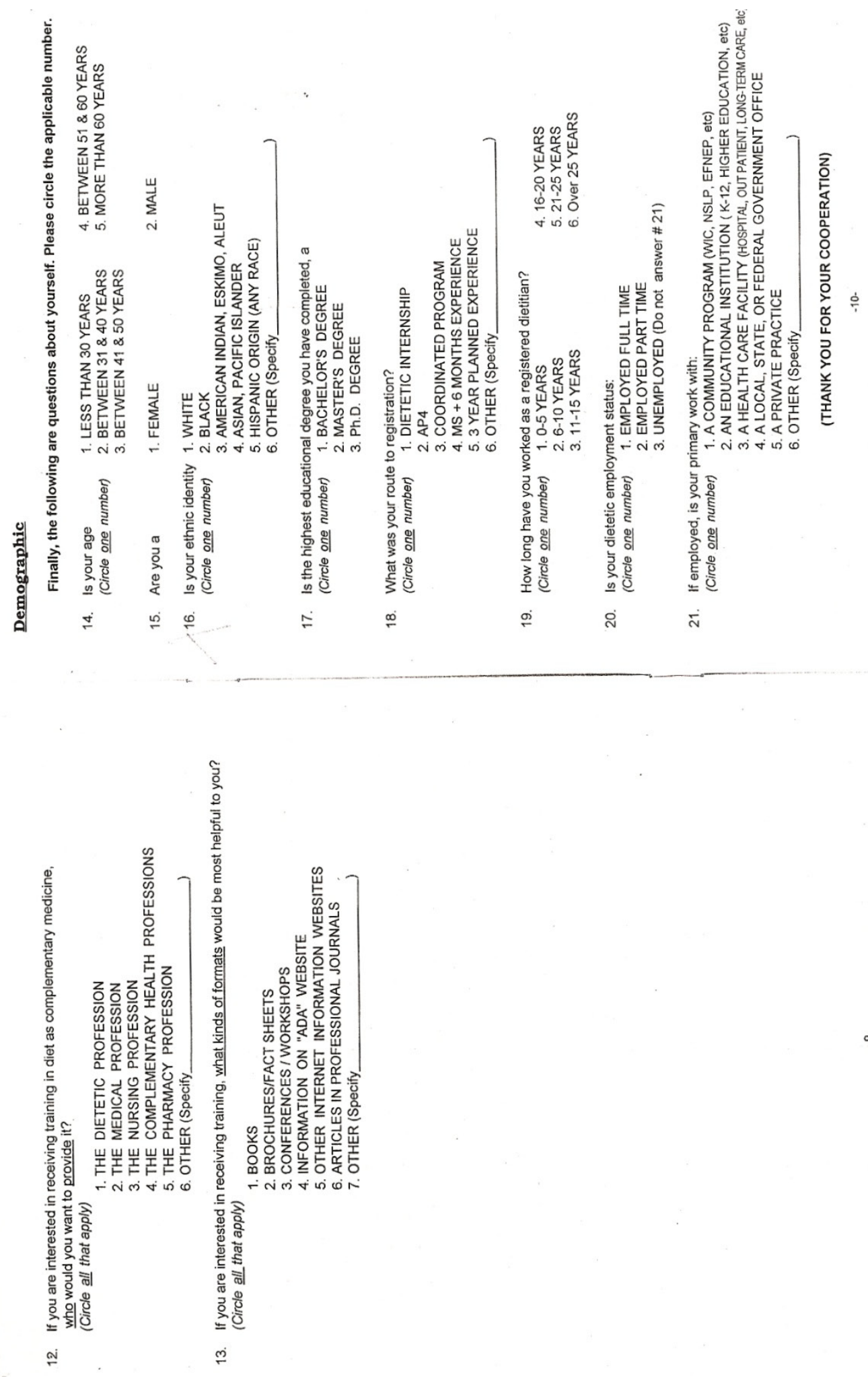
APPENDIX FOUR 


\section{QUESTIONS FOR PILOT STUDY PARTICIPANTS}

1) Did the survey read well?

$\square$ Yes

1a) If NOT, please indicate the specific area and problem.

2) Would you change anything (question, content, directions)?

$\square$ Yes

2a) If YES, please indicate the specific area and problem.

3) Would you add anything (question, content, directions)?

$\square$ Yes

3a) If YES, please indicate the specific area and problem.

4) Would you delete anything (question, content, directions)?

$\square$ Yes

4a) If YES, please indicate the specific area and problem.

5) How long did the survey take for you to complete?

6) Was the wording of the questions easy to understand?

$\square$ Yes 
$\square$ No

6a) If NOT, please indicate the question number and problem.

7) Was the aesthetic look of the survey appealing?

$\square$ Yes

No

7a) If NOT, please indicate what was unappealing and any suggestions for improvement.

8) Any overall suggestions regarding the survey? 
APPENDIX FIVE 


\section{EXPERT PANELIST QUESTIONS}

1) Did the survey read well?

$\square$ Yes

No

1a) If NOT, please indicate the specific area and problem.

2) Would you change anything (question, content, directions)?

$\square$ Yes

2a) If YES, please indicate the specific area and problem.

3) Would you add anything (question, content, directions)?

$\square$ Yes

3a) If YES, please indicate the specific area and problem.

4) Would you delete anything (question, content, directions)?

$\square$ Yes

No

4a) If YES, please indicate the specific area and problem. 
5) How long did the survey take for you to complete?

6) Was the wording of the questions easy to understand?

$\square$ Yes

6a) If NOT, please indicate the question number and problem.

7) Was the aesthetic look of the survey appealing?

$\square$ Yes

7a) If NOT, please indicate what was unappealing and any suggestions for improvement.

8) Any overall suggestions regarding the survey?

It is well known that there are multiple definitions of functional foods and as a result, it is difficult to measure RDs' practical knowledge of this evolving term. Accordingly, each definition has a different set of foods and food types associated with it. So in this respect this is survey has posed a challenge because the interest of this study is to identify RDs knowledge of functional foods.

In order to measure knowledge, there needs to be a correct answer for each question. Therefore, I am asking expert panelists to identify the foods and food types associated with each definition from Question 1 of the Knowledge Section. The goal is to gain a consensus. The definitions are again listed below for reference: 
A) Functional foods are "those that by virtue of physiologically active food components provide health benefits beyond basic nutrition."

B) Functional foods are those that have "satisfactorily demonstrated to affect beneficially one or more target functions in the body beyond adequate nutritional effects in a way that is relevant to either an improved state of health and well-being and/or reduction of risk of disease."

C) Functional foods are "those foods that encompass potentially healthful products including any modified food or ingredient that may provide a health benefit beyond the traditional nutrients it contains."

D) All foods are functional on some physiologic level including “... whole foods, fortified foods, enriched or enhanced foods, have a potentially beneficial effect on health when consumed as part of a varied diet."

E) Functional foods encompass those where "...one or more ingredients (nutrients or non-nutrients) have been added or modified to enhance their contribution to a healthful diet. These foods may have a beneficial effect on health beyond the effect of normal foods. They can improve certain body functions, state of health and/or lower the risk on developing certain diseases."

9) Choose All That Apply: Letters A - E represent the definitions listed above. For each of the five food types listed, please check the boxes indicating which food types are associated with each definition.

\begin{tabular}{|l|l|l|l|l|l|}
\hline FOOD TYPE & \multicolumn{5}{|l|}{ DEFINITION LETTER } \\
\hline & A & B & C & D & E \\
\hline 1) Fortified food products & & & & & \\
\hline 2) Enriched food products & & & & & \\
\hline 3) Unprocessed or natural foods & & & & & \\
\hline 4) Herbal Supplements & & & & & \\
\hline 5) Dietary Supplements & & & & & \\
\hline
\end{tabular}

10) Choose All That Apply: Letters $A$ - E represent the definitions listed above. For each of the foods listed, please check the boxes indicating which foods are associated with each definition.

\begin{tabular}{|l|l|l|l|l|l|}
\hline FOOD ITEM & \multicolumn{6}{|l|}{ DEFINITION LETTER } \\
\hline GRAINS & A & B & C & D & E \\
\hline 1) Chocolate Chip Cookie & & & & & \\
\hline 2) Chocolate Chip Cookie with Fiber & & & & & \\
\hline 3) Cream of Wheat & & & & & \\
\hline 4) Instant Oatmeal & & & & & \\
\hline
\end{tabular}




\begin{tabular}{|l|l|l|l|l|l|}
\hline 5) Low-calorie Bread & & & & & \\
\hline 6) Low-fat Chocolate Chip Cookie & & & & & \\
\hline 7) Multi-grain Bread & & & & & \\
\hline 8) Old Fashioned Oatmeal & & & & & \\
\hline
\end{tabular}

\begin{tabular}{|l|l|l|l|l|l|}
\hline FOOD ITEM & \multicolumn{5}{|l|}{ DEFINITION LETTER } \\
\hline MEAT \& BEANS & A & B & C & D & E \\
\hline 9) Black beans & & & & & \\
\hline 10) Chicken & & & & & \\
\hline 11) Eggs & & & & & \\
\hline 12) Eggs with Omega-3 Fatty Acids & & & & & \\
\hline 13) Ground Beef & & & & & \\
\hline 14) Lentils & & & & & \\
\hline 15) Salmon & & & & & \\
\hline 16) Tuna & & & & & \\
\hline 17) Tilapia & & & & & \\
\hline
\end{tabular}

\begin{tabular}{|l|l|l|l|l|l|}
\hline FOOD ITEM & \multicolumn{5}{|l|}{ DEFINITION LETTER } \\
\hline SUPPLEMENTS & A & B & C & D & E \\
\hline 18) Dietary Fiber & & & & & \\
\hline 19) Echinacea & & & & & \\
\hline 20) Fish Oil & & & & & \\
\hline 21) Flaxseed Oil & & & & & \\
\hline 22) Ginger & & & & & \\
\hline 23) Ginger Root & & & & & \\
\hline 24) Ginkgo Biloba & & & & & \\
\hline 25) Glucosamine & & & & & \\
\hline 26) Prebiotics & & & & & \\
\hline 27) St. John's Wort & & & & & \\
\hline
\end{tabular}

\begin{tabular}{|l|l|l|l|l|l|}
\hline FOOD ITEM & \multicolumn{5}{|l|}{ DEFINITION LETTER } \\
\hline VITAMINS \& MINERALS & A & B & C & D & E \\
\hline 28) Calcium and Vitamin D & & & & & \\
\hline 29) Folate & & & & & \\
\hline 30) Multivitamin & & & & & \\
\hline 31) Vitamin C & & & & & \\
\hline 32) Vitamin E & & & & & \\
\hline
\end{tabular}




\begin{tabular}{|l|l|l|l|l|l|}
\hline FOOD ITEM & \multicolumn{5}{|l|}{ DEFINITION LETTER } \\
\hline VEGETABLES & A & B & C & D & E \\
\hline 33) Avocado & & & & & \\
\hline 34) Carrots & & & & & \\
\hline 35) Garlic & & & & & \\
\hline 36) Guacamole & & & & & \\
\hline 37) Soybean Products & & & & & \\
\hline 38) Soybeans & & & & & \\
\hline
\end{tabular}

\begin{tabular}{|l|l|l|l|l|l|}
\hline FOOD ITEM & \multicolumn{5}{|l|}{ DEFINITION LETTER } \\
\hline FRUITS & A & B & C & D & E \\
\hline 39) Blueberries & & & & & \\
\hline 40) Cranberry Juice & & & & & \\
\hline $\begin{array}{l}\text { 41) Cranberry Juice with } \\
\text { Pomegranate }\end{array}$ & & & & & \\
\hline 42) Ketchup & & & & & \\
\hline 43) Orange Juice & & & & & \\
\hline 44) Orange Juice with Calcium & & & & & \\
\hline 45) Orange Juice with Glucosamine & & & & & \\
\hline 46) Whole Tomato & & & & & \\
\hline
\end{tabular}

\begin{tabular}{|l|l|l|l|l|l|}
\hline FOOD ITEM & \multicolumn{5}{|l|}{ DEFINITION LETTER } \\
\hline OILS \& FATS & A & B & C & D & E \\
\hline 47) Margarine & & & & & \\
\hline $\begin{array}{l}\text { 48) Margarine with Plant Stanols } \\
\text { and Sterols }\end{array}$ & & & & & \\
\hline 49) Olive Oil & & & & & \\
\hline $\begin{array}{l}\text { 50) Olive Oil with Omega-3 Fatty } \\
\text { Acids }\end{array}$ & & & & & \\
\hline
\end{tabular}

\begin{tabular}{|l|l|l|l|l|l|}
\hline FOOD ITEM & \multicolumn{5}{|l|}{ DEFINITION LETTER } \\
\hline MILKS & A & B & C & D & E \\
\hline 51) Yogurt & & & & & \\
\hline 52) Yogurt with Probiotics & & & & & \\
\hline
\end{tabular}

FUNCTIONAL FOOD SUGGESTIONS: PLEASE TYPE IN SPACE PROVIDED AND INDICATE WHICH DEFINITIONS MATCH THE FOOD.

\begin{tabular}{|l|l|l|l|l|l|}
\hline FOOD ITEM & \multicolumn{5}{|l|}{ DEFINITION LETTER } \\
\hline OTHER & A & B & C & D & E \\
\hline 53$)$ & & & & & \\
\hline
\end{tabular}




\begin{tabular}{|l|l|l|l|l|}
\hline & & & & \\
\hline & & & & \\
\hline
\end{tabular}

11) Any suggestions or thoughts regarding the survey? 
APPENDIX SIX 


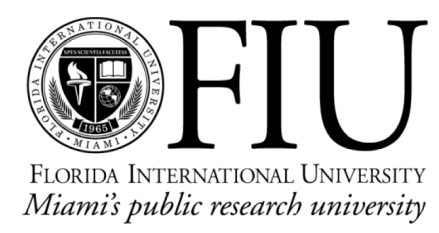

CONSENT FORM

\section{PERCEPTIONS, ATTITUDES AND PRACTICES OF REGISTERED DIETITIANS REGARDING FUNCTIONAL FOODS}

My name is Amanda Berhaupt and I am a graduate student in the Department of Dietetics \& Nutrition at Florida International University in Miami, Florida. I am conducting a research study to determine the perceptions, attitudes and practices of Registered Dietitians (RDs) regarding functional foods. In order to accomplish this, I am requesting your participation to complete the enclosed survey, which will take about 10 minutes. Surveys have been mailed to a sample population provided by the Commission on Dietetic Registration. You were chosen as a potential participant because your attributes match our selection criteria, which include RDs, who are not retired and currently reside within the United States.

By completing the survey, you will contribute to a pool of data that will be used to determine the perceptions, attitudes and practices of RDs and functional foods. Further, the data will identify training and education needs, and facilitate future training opportunities for dietetics professionals.

Please complete the enclosed survey and return it in the enclosed envelope provided by August 3, 2009. Your consent will be given when you complete the survey. You will not be asked for any private information. The data will be reported as a group and may be published however there is no information linking your survey to your person. There are no known risks or benefits to you for your participation in this survey. There is no cost or compensation for completing and returning the survey. Your participation in this study is completely voluntary. You have the right to decline or discontinue participation at any time without consequence. If you choose not to complete the survey no other action is needed.

If you have any questions about this study before or after you complete the survey please contact me at 305-397-9042 or email aberh001@fiu.edu. You may also contact my major professor, Evelyn B. Enrione, $\mathrm{PhD}, \mathrm{RD}$ at 305-348-3236 or email enrionee@fiu.edu. If you have any questions regarding your rights as a participant in this research study you may call Dr. Patricia Price, the Chairperson of the Institutional Review Board at 305-348-2618 or 305-348-2494. Thank you for taking time to participate in this study.

Sincerely,

Amanda Berhaupt

Master's Graduate Student

Department of Dietetics \& Nutrition 
APPENDIX SEVEN 
"Hello, my name is Amanda Berhaupt and I am a graduate student at Florida International University in the department of Dietetics and Nutrition. This is an email regarding my thesis project. I have acquired a list of prospective participants from the Commission on Dietetic Registration to complete my survey on the "Perceptions, Attitudes and Practices of Registered Dietitians Regarding Functional Foods." You are receiving this email because CDR included your contact information in a random sample. Surveys were initially mailed out via the U.S. Postal Service, however the address provided for you was no longer valid. Thus, I have a created a computer version of the survey and emailed those individuals. Attached are two documents; a consent form outlining the purpose of the study, and the survey. I ask that you please fill out the attached survey and email it back to me by September 25, 2009.

INSTRUCTIONS: Please download and save the attached interactive document entitled "RD Functional Food Survey for Graduate Student" to your desktop. All questions are in check box, or type formats and may be completed directly on the PDF document using your computer. Once you have filled in the survey, you must save it again and attach it to your return email.

This document is an Adobe Acrobat interactive PDF form. If you do not have Adobe Acrobat Reader on your computer, you may download it for free here: http://get.adobe.com/reader/. If you prefer to return the survey through regular mail, please use the address and contact information at the bottom of this email.

Lastly, if you have any trouble or have any questions, please feel free to contact me at aberh001@fiu.edu or 305-397-9042. Thank you for your time. I really appreciate your participation."

Amanda Berhaupt

Master's Graduate Student

Florida International University 
APPENDIX EIGHT 
September 25, 2009 (Email)

Good morning, this is a friendly reminder regarding the survey entitled, "The Perceptions, Attitudes and Practices of Registered Dietitians Regarding Functional Foods" for my thesis project. The survey I'm referring to had initially been mailed to you at the beginning of August. The responses received so far have been wonderful and I just need 20 more surveys to meet my quota! If you have lost or thrown out the survey, I would be happy to e-mail you another copy, so you may return it by e-mail.

Thank you for your time and please let me know if I can be of any assistance. Your participation is greatly appreciated!

Amanda Berhaupt

Master's Graduate Student

Florida International University 